\title{
HACIA UN ESTUDIO \\ MULTIDISCIPLINAR DEL PROCESO DE GLOBALIZACIÓN
}

\author{
ADRIÁN OSVALDO RAVIER*
}

Resumen: El objetivo de este artículo es estudiar el proceso de globalización desde una perspectiva multidisciplinar. Primero, a través de un enfoque histórico y evolutivo, donde observaremos que la globalización es una institución originada en el orden espontáneo, tal como lo son también la división del trabajo, el sistema de precios, la moneda, el derecho o el lenguaje. Segundo, a través del análisis económico, donde confrontamos la «libertad de comercio»-que, a través de la eliminación de barreras, da lugar a la dinámica creatividad empresarial_ - versus lo que Gabriel Zanotti denominó como la "globalización del intervencionismo» — donde el Estado todo lo intenta planificar y controlar, generando siempre resultados contrarios a los buscados-. Tercero, desarrollamos una investigación jurídico-institucional, analizando las ventajas del arbitraje y las sanciones no legales, como complemento del enforcement público. Finalmente, nos adentramos en las implicaciones que la globalización ejerce sobre la cultura, criticando el nacionalismo y la «cultura alambrada», para dar lugar a una sociedad abierta y «cosmopolita».

Palabras clave: Proceso de globalización. Estudio multidisciplinar. Orden espontáneo. Intervencionismo. Mitos del comercio internacional. Arbitraje. Lex Mercatoria. Enforcement. Nacionalismo. Cultura alambrada. Escuela Austriaca de Economía.

Códigos JEL: B25, B53, E32, E44, F02.

Abstract: The objective of this article is to study the process of globalization from a multidisciplinary perspective. First, through a historical and evolutionary focus, where we will observe that the globalization is an institution originated

* El autor es Doctor en Economía Aplicada por la Universidad Rey Juan Carlos de Madrid y miembro a tiempo completo del Departamento de Investigaciones de la Fundación Friedrich A. von Hayek. Correo: a_ravier@hayek.org.ar

Procesos de Mercado: Revista Europea de Economía Política Vol. VI, n. ${ }^{-1}$, Primavera 2009, pp. 43 a 102 
in the spontaneous order, just as they are also the division of labor, the price system, the money, the law or the language. Second, through the economic analysis, where we confront the "free trade» —-that, through the elimination of barriers, results in the dynamic entrepreneur creativity - versus what Gabriel Zanotti named as the "globalization of the interventionism» - where the government tries to plan and control everything, always generating results that are just the opposite to those it looked for-. Third, we develop a legal and institutional research, analyzing the advantages of the arbitration and the non legal sanctions, as a complement of the public enforcement. Finally, we go into the implications that the globalization exercises on the culture, criticizing the nationalism and the "fenced culture», to give place to an open and «cosmopolitan» society.

Key words: Globalization process. Multidisciplinary study. Spontaneous order. Interventionism. Myths of the international trade. Arbitration. Lex Mercatoria. Enforcement. Nationalism. Fenced culture. Austrian School of Economics.

JEL codes: B25, B53, E32, E44, F02.

\section{I \\ INTRODUCCIÓN}

La «ingeniería social» se encuentra instalada en toda la sociedad global. En todas las naciones, con diferente grado, los individuos conviven con la fatal arrogancia de quienes intentan planificar un orden social e institucional ajeno a lo que la interacción de sus voluntades determina. En este sentido, Alberto Benegas Lynch (h) y Carlota Jackisch definen a la «ingeniería social» como «una concepción según la cual es posible racionalmente elegir una meta política última o un Estado ideal aun antes de emprender actividad política alguna. La idea es diseñar un plano de lo que la sociedad debería ser y luego considerar el camino y los medios más adecuados.» ${ }^{1}$

Emerge sin embargo en la sociedad un proceso que viene a confrontar este racionalismo constructivista. Los planificadores, que

1 Véase Alberto Benegas Lynch (h) y Carlota Jackisch (2003a), El fin de las libertades: el caso de la ingeniería social, Fundación Friedrich A. von Hayek, en colaboración con Guillermo Rodríguez y Roberto Dania, p. 18. 
todo lo intentan controlar, se encuentran ahora con un proceso que viene a imponer batalla. Un proceso que no surgió en estos últimos años, ni siquiera en el último siglo. Es más bien un proceso cuyo origen se encuentra en paralelo con el origen del comercio, y que se ha extendido a lo largo de los siglos. Su origen surge espontáneamente de la interacción de diversos individuos en el mercado y su resultado representa un orden abstracto o extendido que ninguno de esos individuos tenía en cuenta al actuar. Este proceso, es el de la globalización.

El objetivo de este trabajo es justamente encaminarnos hacia un estudio «multidisciplinar» de este proceso, ya que entendemos que un análisis de la realidad social deberá incluir al menos un enfoque histórico y evolutivo, una investigación económica, un análisis institucional-jurídico, y finalmente un estudio que profundice sobre sus implicaciones culturales. Este análisis multidisciplinar se hace esencial cuando lo que queremos comprender son los hechos enormemente complejos que observamos en este mundo cambiante, versátil, dinámico.

Como observaremos más adelante, resulta fundamental aquí el tratamiento especialmente dinámico diseñado por los autores de la Escuela Austríaca, que se opone al desarrollado por el Mainstream neoclásico que hoy domina la Ciencia Económica, con sus modelos matemático-funcionales y absurdamente estáticos. ${ }^{2}$

\section{II \\ EL PROBLEMA DE LA DEFINICIÓN}

Ha sido una costumbre en Hayek definir los términos antes de proceder a estudiarlos, y mucho más aún cuando éstos se prestan a cierta ambigüedad. ${ }^{3}$ En este sentido, recurriremos a continuación

2 Para comprender las diferencias entre estos dos enfoques se recomienda la lectura del trabajo de Jesús Huerta de Soto, «La Escuela Austríaca Moderna frente a la Neoclásica», aparecido originalmente en la Revista de Economía Aplicada, Vol. V, invierno de 1997. Compilado luego en Jesús Huerta de Soto (2002), Nuevos Estudios de Economía Política, Unión Editorial, Madrid.

3 Véase Friedrich A. von Hayek (1968), Individualismo: verdadero y falso, Centro de Estudios sobre la Libertad, Buenos Aires. 
a considerar críticamente algunas definiciones alternativas del proceso de globalización, a nuestro juicio incompletas, pero que nos permitirán luego formar una apropiada definición del concepto.

Una primera definición la tomaremos del diccionario de la Real Academia Española, donde globalización, es «la tendencia de los mercados y las empresas a extenderse alcanzando una dimensión mundial que sobrepasa las fronteras nacionales».

Ciertamente, esta definición alude a la globalización desde una perspectiva económica (al mencionar a los mercados y las empresas) e impide hablar de un proceso de globalización anterior a la existencia de las fronteras nacionales, punto que refutaremos al analizar desde una perspectiva histórica, el origen de la globalización.

La definición de la Real Academia implica entonces que dicho proceso no se limita a un pueblo, ciudad, provincia o nación particular, sino que se extiende a lo ancho y a lo largo del orbe. Es decir que implica un proceso de internacionalización.

Una segunda definición, la obtendremos de la enciclopedia libre de internet, Wikipedia, donde la globalización es «el proceso por el que la creciente comunicación e interdependencia entre los distintos países del mundo unifica mercados, sociedades y culturas, a través de una serie de transformaciones sociales, económicas y políticas que les dan un carácter global. Así, los modos de producción y de movimientos de capital se configuran a escala planetaria, mientras los gobiernos van perdiendo atribuciones ante lo que se ha denominado la sociedad en red.»

Aquí la definición parece ser mucho más rica. En primer lugar, define a la globalización como un proceso, más que como una tendencia. En segundo lugar, apunta a la comunicación y la interdependencia de los distintos países del mundo como factores determinantes, que permiten unificar mercados, sociedades y culturas, lo que abre ya el panorama a otras perspectivas diferentes de la economía. Y en tercer lugar, se explicita la pérdida de atribuciones por parte de los gobiernos nacionales.

Una tercera definición la alcanzamos a través de Juan Carlos de Pablo, quien define globalización como «una consecuencia de la formidable reducción de los costos de transporte y comunicación», 
que «surge de muchísimas decisiones adoptadas simultáneamente, de manera no coordinada.» 4

Es curioso que Juan Carlos de Pablo, un economista que no se caracteriza por defender el pensamiento austríaco adjudique aquí el origen de este proceso a lo que en la tradición austríaca es conocido como el «orden espontáneo». Al decir «muchísimas decisiones» alude a los diversos individuos que componen la sociedad, y decisiones «simultáneas pero no coordinadas» implica que estas personas no tenían en mente el resultado que estaban creando.

Para ser más explícitos, este proceso no surge por decisión de nadie: ni del gobierno norteamericano, ni de la familia Bush, ni del FMI o de cualquier otro organismo multilateral de créditos, ni de Bill Gates, ni de ningún capitalista que busque aprovecharse de la pobreza de los individuos que viven en el llamado, «tercer mundo», ni tampoco del «grupo de los siete».

Esta definición entonces, a pesar de carecer de los elementos señalados en las definiciones anteriores, nos introduce dos nuevos elementos: Por un lado, determinar su origen espontáneo, y por otro «la formidable reducción de costos de transporte y comunicación».

Una cuarta definición la tomamos de Richard Ebeling al explicar que la «Globalización se transformó en la palabra de moda para un proceso que se ha venido desarrollando con una creciente intensidad por más de 200 años - la internacionalización de la división del trabajo-.»5

Este es un elemento fundamental, del que carecíamos en las anteriores definiciones: «la internacionalización de la división del trabajo». Esto implica, entre otras cosas, un aumento en la productividad, una reducción en los costes de producción, mayor competencia, mayor riqueza y fundamentalmente una reducción progresiva de la pobreza.

${ }^{4}$ Véase Juan Carlos de Pablo (2001), La Globalización y cada uno de nosotros, Consejo Empresarial Argentino.

${ }^{5}$ Véase Richard Ebeling (2002), «Book Review: The Race to the Top: The Real Story of Globalization by Tomas Larsson», The Future of Freedom Foundation, February 2002. Traducido al español por Hernán Alberro para la Fundación Atlas para una Sociedad Libre, «La Carrera hacia la Cima, la verdadera historia de la globalización». 
Sintetizando, podemos observar en los distintos autores mencionados los siguientes elementos de la globalización: a) es un proceso; b) originado espontáneamente en el mercado; c) desarrolla una progresiva internacionalización de la división del trabajo; d) reduce costes de transporte y de comunicación; e) implica una integración cultural, política, económica; y f) jamás debemos olvidar el individualismo metodológico. Hablar de macro-agregados no nos debe impedir ver que siempre debemos estudiar a aquellos agentes cuya existencia es real. Recordemos que no existe tal cosa como «sociedad», «gobierno» o «clases sociales», entre muchas otras metáforas que comúnmente se utilizan en las teorías colectivistas. Es que como explica Hayek, «no hay otro camino para tratar de entender los fenómenos sociales, sino a través de nuestra comprensión de las acciones individuales dirigidas hacia otras personas y guiadas por su esperada conducta». 6

De esta forma, definiremos «Globalización» como aquel proceso que surge espontáneamente en el mercado y que actúa desarrollando una progresiva división internacional del trabajo, eliminando restricciones a las libertades individuales, reduciendo costes de transporte y de comunicación e integrando progresivamente a los individuos que componen la "gran sociedad».

Habiendo definido el proceso que es objeto de estudio, podemos pasar a analizarlo bajo las distintas perspectivas comentadas en la introducción.

\section{III \\ LA PERSPECTIVA HISTÓRICA DEL PROCESO DE GLOBALIZACIÓN}

Se ha comentado previamente que es costumbre en la tradición de la Escuela Austríaca definir los conceptos sobre los que en nuestro estudio ahondaremos. Debemos agregar aquí, que también es una conocida preocupación en esta tradición, encabezar

\footnotetext{
6 Véase Friedrich A. von Hayek (1968), op. cit., p. 20.
} 
las reflexiones teóricas con breves ensayos historiográficos sobre el tema específico que se propondrá abordar.

Según la definición que hemos ensayado, la Globalización es un proceso que, entre otras cosas, está vinculado a la evolución del comercio, y fundamentalmente a la especialización. Por ello, resultará central en este trabajo el capítulo III de la última obra de Hayek, La Fatal Arrogancia, al que tituló «La evolución del mercado: el comercio y la civilización", y donde el autor ensaya comentarios fundamentales para el estudio del origen del comercio y su evolución. ${ }^{7}$

El proceso de globalización por supuesto, no es un fenómeno nuevo en la historia económica mundial. O'Rourke y Williamson, por ejemplo, comentan que «los economistas que se ocupan de la globalización tratan el fenómeno como si fuera exclusivo de nuestro tiempo, ignorando todo lo que el anterior episodio le puede enseñar al actual.» ${ }^{8}$

Comentamos previamente que el mismo Richard Ebeling describía la globalización como un proceso que «se ha venido desarrollando con una creciente intensidad por más de 200 años», sin embargo, no encontramos el origen de este proceso alrededor de los últimos años del siglo XVIII. Tampoco lo encontramos en el siglo XVI, cuando las potencias europeas descubrieron el «nuevo mundo». Ni siquiera con la expansión del imperio romano cuando bajo sus diversos emperadores unificó Europa.

Si bien desde la Revolución Industrial las innovaciones tecnológicas permitieron una mayor aceleración del proceso, la tendencia hacia el intercambio, la cooperación y, porque no, la integración, se viene gestando desde la más remota antigüedad. Comenzó operando sobre tribus y clanes, quienes traspasaban sus fronteras para realizar intercambios, y luego se extendió a pueblos, ciudades, provincias, estados e imperios.

Debemos retroceder mucho más y analizar el origen del comercio, quizás allí encontremos una aproximación más certera.

\footnotetext{
7 Véase Friedrich A. von Hayek (1990) [1988], La Fatal Arrogancia. Los Errores del Socialismo, ESEADE, Obras Completas, Volumen 1, Buenos Aires; y Unión Editorial, Madrid.

8 Véase Kevin H. O’Rourke y Jeffrey G. Williamson (1999), Globalization and History, MIT Press.
} 


\section{Origen y evolución del comercio}

En el mencionado tercer capítulo de su Fatal Arrogancia, Hayek demuestra con sucesivas referencias a trabajos históricos, arqueológicos y antropológicos que el comercio data de los tiempos más remotos.

Un ejemplo lo representa el trabajo del arqueólogo Leakley, quien afirma que «la actividad comercial supera en antigüedad a la agrícola, así como a cualquier otra modalidad productiva regular». ${ }^{9} \mathrm{O}$ las obras de Herskovits, quien afirma que «en el continente europeo hay indicios de comercio entre puntos muy alejados en la época paleolítica, es decir, hace casi 30.000 años.» ${ }^{10}$

Hayek comenta que ocho mil años atrás, Catal Hüyük en Anatolia y Jericó en Palestina se habían convertido en centros comerciales entre el Mar Negro y el Mar Rojo, incluso antes de que hubiera aparecido el comercio de la cerámica y los metales. Uno y otro representaban incipientes ejemplos de esos «dramáticos aumentos de población» a los que en ocasiones se alude mediante la expresión «revoluciones culturales».

Con posterioridad, y a través de sucesivas referencias, Hayek demuestra que «a finales del séptimo milenio antes de Cristo existía ya una red de rutas comerciales, tanto marítimas como terrestres, a través de las cuales la obsidiana se enviaba desde la isla de Melos hasta la tierra firme» de Asia Menor y Grecia.

Hay también pruebas de la existencia de extensas redes comerciales entre Beluchistán (Paquistán occidental) y determinadas regiones del continente asiático, incluso con anterioridad al año 3200 a.C.

Por último, sabemos a través de Pirenne que la economía del Egipto predinástico descansaba firmemente en el intercambio mercantil. ${ }^{11}$ p. 212.

9 Véase Richard E. Leakey (1981), The Making of Mankind, Nueva York, Dutton,

${ }_{10}$ Véase Melville J. Herskovits (1948), Man and His Works; y Economic Anthropology, A study in Comparative Economics, ambos editados en: Nueva York, Alfred A. Knopf, Inc.

11 Véase Jacques Pirenne (1934), Histoire des institutions et du droit privé de l'ancienne Egypte, Bruselas, edición de la Fondation Egyptologique Reine Elisabeth. 
La gran expansión de la actividad comercial, propiciadora de la subsiguiente pujanza de la civilización clásica, tuvo lugar, según la ciencia arqueológica, incluso en los remotos tiempos de los que casi carecemos de documentación histórica, es decir, en los siglos situados entre los años 750 y 550 antes de Jesucristo. Dicha expansión mercantil parece haber dado lugar en aquella época a un notable incremento demográfico de los centros comerciales griegos y fenicios, que rivalizaron entre sí en el establecimiento de colonias, hasta el extremo de que al principio de la era clásica todos dependían vitalmente de una actividad mercantil regular.

No cabe, por lo tanto, dudar de la existencia de cierta actividad comercial aun en los más primitivos estadios de la historia, así como de su decisiva influencia en la gestación de órdenes más extensos.

Tal proceso sin embargo, advierte Hayek, «sólo lograría avanzar entre grandes dificultades, e implicaría, sin duda, la ruptura de muchos lazos tribales. Una vez surgido, incluso, algún tipo de consenso sobre la conveniencia de respetar la propiedad plural, ciertas prácticas antes inimaginables debieron ser toleradas para que las comunidades llegaran a permitir que, en beneficio de gentes foráneas, y al objeto de subvenir necesidades sólo parcialmente susceptibles de identificación por parte de los propios comerciantes - por no aludir a la población en general-, se exportaran ciertos artículos apetecidos por la comunidad que, de otro modo, habrían sido dedicados a satisfacer determinadas necesidades locales.» ${ }^{12}$

Un ejemplo en este sentido, lo constituyen los navegantes de los incipientes centros comerciales griegos, que transportaban vasos de cerámica llenos de aceite o vino al Mar Negro, Egipto o Sicilia, para recibir grano a cambio; sustraían ciertamente del abastecimiento local unos recursos codiciados por quienes habitaban ese más próximo entorno, y todo ello en beneficio de gentes de las que aquellas poblaciones casi nada sabían.

Stuart Piggot por su parte, explica que «los descubridores de nuevos recursos y los que posteriormente los aprovechaban, los

12 Véase Friedrich A. von Hayek (1990) [1988], op. cit., p. 81. 
comerciantes e intermediarios, los organizadores de navegaciones y caravanas comerciales, las concesiones y tratados, el concepto de la foraneidad, así como los diferentes hábitos vigentes en las diversas zonas geográficas, todo ello contribuyó a la ampliación de los entornos sociales exigida por el acceso de la humanidad a un nuevo nivel tecnológico..., a la edad de bronce». ${ }^{13} \mathrm{Y}$ agrega Hayek, en referencia al citado autor, que refiriéndose a la edad de bronce intermedia correspondiente al segundo milenio, afirma también que «la existencia de las redes de comunicación marítimas, fluviales y terrestres otorgó carácter internacional a gran parte de las manufacturas del cobre de aquella época. Idénticas técnicas y estilos se repiten a lo largo y a lo ancho de Europa.»

El comercio así, dio lugar a la civilización sedentaria en nuevos lugares, lo que consiguientemente permitió una mayor especialización, procesos que culminarían finalmente en las expansiones demográficas. Se inició así, una especie de reacción en cadena en virtud de la cual la incrementada densidad poblacional facilitaba el descubrimiento de nuevas oportunidades de especialización, lo que permitía una ulterior expansión de la división del trabajo, propiciadora a su vez de nuevos aumentos de población y mayores niveles de vida y, por ende, de nuevos incrementos demográficos, y así sucesivamente.

\section{Las primeras aceleraciones del proceso}

Quizás una primera aceleración del proceso de globalización se observe en el siglo XV y XVI con la expansión naval de varias potencias europeas, que recorren la Tierra conquistando, colonizando y desarrollando intercambios comerciales en una escala nunca vista hasta entonces. A partir de esta época se opera un proceso acumulativo de transformaciones que continúa firmemente en la misma dirección hasta nuestros días, acelerándose a veces de un modo impresionante.

13 Véase Stuart Piggot (1965), Ancient Europe from the beginning of Agriculture to Classical Antiquity, Edimburgo, Edimburgh University Press, p. 22. 
Richard Ebeling comenta sobre este período:

«Pero fue sólo luego de las grandes exploraciones de los siglos XV y XVI, con la apertura de nuevas rutas de comercio desde Europa hacia África y Asia y el descubrimiento del "Nuevo Mundo", que la era moderna de comercio internacional comenzó su desarro1lo. Ha seguido una trayectoria en aumento desde el siglo XVIII, a medida que tanto los medios tecnológicos como el orden institucional permitían la potencialidad del comercio global para expandirse en forma increíble.» ${ }^{14}$

Una segunda aceleración, la representa entonces la primera revolución industrial. Definiremos «Revolución Industrial», siguiendo a David Landes, como a un «complejo de innovaciones tecnológicas que, al sustituir la habilidad humana por maquinaria, y la fuerza humana y animal por energía mecánica provoca el paso desde la producción artesanal a la fabril, dando así lugar al nacimiento de la economía moderna.» ${ }^{15}$ La Revolución Industrial se inició en Inglaterra en el siglo XVIII, se expandió desde allí por los países de Europa continental y por algunas otras pocas áreas, y transformó en el espacio en menos de dos generaciones, la vida del hombre occidental, la naturaleza de la sociedad y sus relaciones con los demás pueblos del mundo. Los avances tecnológicos tuvieron lugar en tres áreas: 1) la capacidad humana fue sustituida por instrumentos mecánicos; 2) la energía inanimada - y en especial el vapor de agua - ocupó el lugar de la energía humana y animal; 3) se realizaron grandes mejoras en los métodos de obtención y elaboración de materias primas, especialmente en los campos que hoy conocemos como industria metalúrgica y química.

Junto a estos cambios en equipo y en métodos se desarrollaron nuevas formas de organización industrial. El taller y la unidad de trabajo familiar fueron sustituidos por la nave industrial y la fábrica.

\footnotetext{
14 Véase Richard Ebeling (2002), op. cit.

15 Véase David Landes (1979), Progreso tecnológico y Revolución industrial, Madrid, Tecnos, p. 15.
} 
Se registraron importantes avances en la producción de hierro, textiles y productos químicos, los que requirieron de grandes progresos en el transporte, por tierra y por mar, para llevar los bienes desde el origen de las materias primas hasta las fábricas y desde éstas hacia los mercados, próximos o lejanos. Esto abrió oportunidades que, en combinación con las posibilidades tecnológicas, dieron lugar al ferrocarril y la navegación a vapor, y que contribuyeron, naturalmente, a aumentar la demanda de hierro y combustible a la vez que ampliaban los mercados para los productos industriales. Y así sucesivamente, en círculos progresivamente expansivos.

Explica David Landes, que «la Revolución Industrial marcó un hito fundamental en la historia del hombre. Hasta entonces, los avances en el comercio y la industria, incluso los más rentables y espectaculares, habían sido esencialmente superficiales: más riqueza, más bienes, ciudades más prósperas, mercados enriquecidos. El mundo había experimentado otros períodos de prosperidad industrial - la Italia medieval y Flandes, por ejemplo- y había visto cómo corrientes de progreso económico acababan por retroceder en cada caso; en ausencia de cambios cualitativos, de mejoras en la productividad, nada garantizaba la consolidación de mejoras puramente cuantitativas. Con la Revolución Industrial se inició un proceso acumulativo de avance tecnológico autoalimentado cuyas repercusiones se harían sentir en todos los aspectos de la vida económica.»16

En palabras de Richard Ebeling,

«La maravilla del siglo XIX fue el transporte terrestre, más que la máquina a vapor, fue el tren. La primera línea de tren se abrió hacia 1829 entre Liverpool y Manchester en Gran Bretaña. Permitía a los viajantes llegar a destino a una velocidad impresionante de 25 kilómetros por hora. Hacia finales del siglo XIX, las vías de tren cruzaban gran parte de la Europa Occidental y Central, y se estaban extendiendo en Europa Oriental.

En 1869 -el mismo año en el que se abrió el Canal de Suezse unió el primer tren transcontinental cruzando Estados Unidos

16 Véase David Landes (1979), op. cit., p. 17. 
fuera de Ogden, Utah. Y la inversión de capital extranjero en Europa estaba construyendo redes ferroviarias en Sudamérica, Asia, y Australia. Hoy, a principios del siglo XXI, un viaje de un día y medio en avión puede llevar a una persona hacia casi cualquier gran ciudad del otro lado del mundo desde cualquier punto. El tiempo de viaje en avión a través del Atlántico o cruzando Estados Unidos continental es ahora cuestión de horas, más que de días o semanas.» ${ }^{17}$

La revolución en transportes y comunicación que comenta Ebeling, impactó tanto sobre los mercados internacionales de capital, como sobre los mercados laborales y de bienes. Recordemos que sesenta millones de europeos emigraron en los 100 años después de 1820: tres quintos a Estados Unidos, muchos otros dentro de Europa y un porcentaje importante a los países Latinoamericanos, encabezados por Argentina. La mayoría de los europeos buscaba escapar de la pobreza y en el continente americano los salarios eran relativamente más altos.

El proceso de globalización jugó así un papel fundamental en la convergencia de la remuneración de los factores productivos, en los diferentes países. ${ }^{18} \mathrm{~A}$ fines del siglo XIX la convergencia salarial se dio principalmente entre una Europa intensiva en mano de obra, con bajos salarios, acercándose al alto poder adquisitivo del salario en las Américas, y con Argentina y Canadá acercándose a Australia y Estados Unidos. Sin duda, la convergencia de salarios entre 1850 y 1914 se debió a la fuerza de la apertura de la economía, tanto comercial como migratoria.

Como señala Jorge Avila, «la internacionalización fue la regla. Se hacían conferencias para estandarizar casi todo, desde pesos

17 Véase Richard Ebeling (2002), op. cit.

18 Quizás aquí existe un punto de contacto por analizar entre las teorías defendidas por la Escuela Austriaca y el Mainstream. Heckscher (1919) y Ohlin (1933) sostuvieron que el comercio internacional de bienes generaría una tendencia hacia la igualación del precio de los factores, actuando entonces como sustituto parcial de la migración internacional de trabajadores y capital. Este modelo, al que hoy se conoce como el «Modelo Heckscher-Ohlin», se encuentra en la actualidad en todos los manuales y tratados de Economía Internacional. 
y medidas hasta el correo. La adopción del patrón oro fue la expresión de este proceso en el plano monetario.» ${ }^{19}$

Hasta John Maynard Keynes, en «Las Consecuencias Económicas de la Paz» de 1919 hizo una excepcional descripción de la Europa globalizada anterior a la primera guerra mundial:

«Mientras desayunaba en su cama, el habitante de Londres podía ordenar por teléfono los productos más variados de toda la tierra, en las cantidades que fueran necesarias y esperar su pronta entrega en la puerta de su casa. (Describe el funcionamiento de un sistema de libre comercio internacional). Esa persona también podía invertir por teléfono parte de su riqueza en la explotación de recursos naturales y en otras empresas en cualquier rincón del mundo, y así compartir el fruto de esas inversiones (Explica la gran movilidad internacional de capitales existente y la ausencia de riesgos de expropiación o devaluación) Y también podía subirse a barcos y trenes baratos y confortables para viajar a cualquier país sin pasaporte u otra formalidad; podía mandar a un empleado al banco a comprar oro amonedado y luego embarcarse a países extranjeros sin conocer sus religiones, lenguas o costumbres, y considerarse muy mal tratado ante la más mínima interferencia. (Se refiere al espíritu cosmopolita de entonces.) [...]

Pero lo más importante era que aquella persona creía que ese estado de cosas era algo normal, cierto y permanente; creía que el cambio sólo era posible para mejor, y que cualquier desvío de lo previsto era aberrante, escandaloso y evitable. El militarismo y el imperialismo, las rivalidades raciales y culturales, los monopolios, las restricciones (como pasaportes, cuotas de comercio o controles de cambio) y la exclusión, que después asumirían el papel de la serpiente en este paraíso, eran poco más que curiosidades de los diarios, y parecían no ejercer ninguna influencia en el curso ordinario de la vida social y económica, cuya internacionalización era prácticamente completa.» ${ }^{20}$

19 Véase Jorge Avila (2004), ¿Qué es la globalización? Consecuencias para la Argentina y la región, Fundación Atlas 1853, conferencia presentada en el Congreso de la Nación, 15 de septiembre de 2004.

20 Véase Jorge Avila (2004), op. cit. Los acertados comentarios en cursivas han sido agregados por Jorge Avila en la citada conferencia. 
¿Qué ocurrió con aquel estado de cosas? ¿Qué ocurrió con aquel mundo libre que tantos progresos trajo para la sociedad libre? Jorge Avila nos da una respuesta:

«Aquel mundo próspero y cosmopolita fue destruido por dos hechos y por un cambio ideológico: la Primera Guerra Mundial y la Gran Depresión, y el repudio de la doctrina liberal que fue una reacción a tales sucesos. La Primera Guerra Mundial creó una profunda desilusión con respecto al sistema democrático y al internacionalismo. La década de 1920 trajo el proteccionismo, la hiperinflación y las devaluaciones. Y la Gran Depresión destruyó la confianza en el capitalismo y la competencia, y puso al Estado en el centro de la escena económica.» ${ }^{21}$

Pero debemos agregar un punto más a las causas de esta debacle: Las más prestigiosas Universidades del mundo abrazaron el comunismo de Marx y el intervencionismo keynesiano, reemplazando las ideas de los clásicos y de la Escuela Austríaca de Economía misma, y revitalizando las falacias de la Escuela Mercantilista. La ortodoxia liberal fue reemplazada, por el pragmatismo marxista-keynesiano. A partir de allí, el Estado comenzó a crecer a expensas de las libertades individuales de la sociedad. Basta con señalar que antes de la primera guerra mundial, el porcentaje de gasto público sobre PIB (producto interno bruto) jamás superaba el 10\%, mientras que a partir de la década del ' 50 del siglo XX, el creciente gasto público ya se debatía entre un 30 y un $70 \%$ del PIB. En otras palabras, en muchos casos, más de la mitad del tiempo que trabajamos, lo hacemos para sostener al Estado.

La ingeniería social emergió entonces en los años treinta y desde entonces ha sido inútil cualquier intento por detenerla. Año tras año, en los congresos (diputados y senadores) de todas las naciones se debaten cuánto debe ser el aumento del presupuesto a otorgarse a los distintos ministerios (Economía, Seguridad Social, Educación, Salud, Defensa, Trabajo, y en algunos países como el nuestro hasta Producción y Planificación). El debate jamás consiste en dar

21 Véase Jorge Avila (2004), op. cit. 
un paso atrás con alguna política previa sino avanzar sobre las libertas individuales. Pero esto ya lo estudiaremos en el apartado siguiente, correspondiente al análisis económico. Profundicemos ahora, en la actual aceleración del proceso de globalización.

\section{La actual aceleración del proceso de globalización}

En la actualidad, lo que podríamos denominar como la «Tercera Revolución Industrial» ha cambiado nuevamente la forma de vida, en todo sentido, de la Aldea Global. La velocidad de las comunicaciones ha cambiado radicalmente las relaciones humanas en todos los niveles. El conocimiento y la información se hacen accesibles mucho más rápido y, más importante aún, a un coste mucho menor.

Mientras que en el siglo XX aparecía la radio y la televisión, que permitieron la transmisión de voz e imágenes vivas de cualquier parte del globo en cualquier momento a tiempo, ahora, Internet, permite enviar mensajes y documentos adjuntos en forma virtual hacia cualquier punto del planeta en forma instantánea y a bajísimo coste. A esto debemos sumar la comunicación por satélites, la telefonía celular, el fax, las fibras ópticas y la ingeniería genética. El tiempo y el espacio se han comprimido en forma impresionante, especialmente durante el último medio siglo.

Estos avances reducen de un modo notable el coste de muchos bienes de capital, aumentando a su vez su movilidad y versatilidad. Facilitan el control computarizado de la producción y hacen posible la creación de nuevos productos que inundan los mercados. Las comunicaciones más eficientes y baratas y las nuevas herramientas de trabajo obligan a modificar la tradicional organización de la empresa, buscando mayor flexibilidad para adaptarse al cambio.

En este contexto, explica Juan Carlos de Pablo, «la realidad de cada uno de nosotros depende de muchísimas decisiones que en cada momento otros seres humanos adoptan de manera no coordinada, mientras que en la antigüedad dependía principalmente de las de mis vecinos. Dicha realidad no es aleatoria, pero a cada uno de nosotros se nos aparece así, por la enorme dificultad de 
predecir los cambios en un contexto globalizado. Los historiadores reconstruyen los hechos y encuentran, muchas veces con precisión milimétrica, el lugar y el momento en el que comenzó el vuelo de la mariposa que terminó generando un terremoto. De la misma manera que, cotidianamente, después del cierre de la Bolsa de Nueva York, "expertos" en los mercados financieros explican con lujo de detalles por qué ocurrió lo que ocurrió con el Dow Jones, el Nasdaq, etc. Pero si hoy es todo tan claro; ¿por qué no lo dijeron ayer? Porque lo que hoy es "evidente", ayer no había como saberlo».22

Y Lester Thurow concluye: «Por primera vez las empresas pueden comprar en cualquier parte del globo, en la que los costos sean mínimos, y vender en cualquier parte del globo, en la que los precios sean los más altos. El $80 \%$ de las ventas de la más norteamericana de las compañías norteamericanas, Coca Cola, ocurre fuera de Estados Unidos, y el más norteamericano de los productos norteamericanos, el automóvil, se construye a base de componentes fabricados en otros lugares del Mundo.» 23

Hans Sennholz por su parte, nos comenta que las barreras al comercio internacional siguen cayendo, y la «globalización» sigue avanzando. De acuerdo con la Organización Mundial de Comercio, el volumen del comercio está creciendo a una tasa anual del 6 por ciento, y excediendo los 5 billones de dólares. Unas 60.000 compañías transnacionales con más de 500.000 filiales en el exterior están invirtiendo anualmente 400 mil millones de dólares en plantas y equipos fuera del país en donde se encuentra su casa matriz. Sony, Gillete, Ford, General Electric y muchas otras corporaciones reconocidas están produciendo unos 11 billones de dólares en bienes y servicios, excediendo el producto interno bruto de los Estados Unidos, lo cual incluye una importante participación de compañías extranjeras. ${ }^{24}$

Por supuesto Sennholz comprende que no todas son buenas noticias, ya que destaca que existen actualmente unos treinta

22 Véase Juan Carlos de Pablo (2001), op. cit.

23 Véase Lester Thurow (2000), Construir riqueza, Vergara.

24 Véase Hans Sennholz, Globalization Under FIRE, Daily Article, Ludwig von Mises Institute. 
conflictos militares, de diferente tamaño e intensidad, a la vez que aún no se han eliminado todas las barreras al comercio internacional. Sin embargo, manifiesta que la globalización (el slogan actual para hablar de temas de comercio exterior) ha relajado los controles y le ha dado al sector privado un rol fundamental en la producción económica.

\section{Primera conclusión}

Esta descripción histórica y evolutiva que desarrollamos sobre el proceso de globalización busca únicamente, siguiendo a Hayek, encabezar las reflexiones teóricas que en los siguientes tres apartados describiremos.

Pero no queremos cerrar el primer apartado sin comentar algunas primeras conclusiones, bajo la perspectiva presentada.

En primer lugar, el análisis historiográfico demuestra que las importantes aceleraciones del proceso de globalización coinciden con sucesos tecnológicos vinculados con las comunicaciones, antes que un fenómeno económico, político o jurídico. ${ }^{25}$

Segundo, debe quedar claro que el origen del proceso de globalización, tal como el lenguaje, el comercio, la división del trabajo, el dinero y el derecho, entre muchas otras, son instituciones cuyo origen se encuentra en el designio humano, mas nunca en el diseño humano. Nadie pretendió deliberadamente crear un proceso semejante, con las características predichas. Más bien, el proceso surge espontáneamente, de la interacción de los individuos en sociedad, buscando sus propios fines individuales. En palabras del mismo Hayek:

«Cuanto más se profundiza en el estudio de la historia de los procesos económicos, más errónea aparece la tesis según la cual el establecimiento del poder político dotado de un alto nivel de organización marcó el inicio de la civilización. Mucho se exagera en torno al papel desempeñado por los gobernantes en el devenir

25 Véase Alberto Benegas Lynch (h) y Carlota Jackisch, Librecambio y división de poderes, Fundación Hayek y Ediciones Lumiere SA, Buenos Aires, 2002, p. 123. 
histórico debido a que, obviamente, nos ha llegado mucha más información acerca de lo que ellos hicieron que de lo que la coordinada actividad individual iba consiguiendo. [...]

El proceso de extensión del comercio a nuevas áreas fue más entorpecido que facilitado por los poderes públicos. Los pueblos que otorgaron libertad de movimientos y seguridad al comerciante viéronse beneficiados por el hecho de acceder al aprovechamiento de una superior cantidad de información, gracias a su mayor densidad demográfica.» ${ }^{26}$

Tercero, quisiéramos destacar algunas palabras que Hayek menciona en su análisis sobre el origen del comercio, que comentamos al inicio de este apartado. Allí, Hayek explica que el hecho de que «la especie humana haya logrado cubrir por completo la superficie del planeta, así como el que haya sido capaz de alimentar la nutrida población que hoy la integra, incluso en zonas geográficas apenas capaces de producir ni uno solo de los elementos imprescindibles a su supervivencia, son hechos que derivan de su especial capacidad de aprovechar, a lo largo de ese proceso de incontenible expansión que alcanza las regiones más remotas de la tierra, los específicos recursos locales que la economía global precisa.» 27

Y en una referencia que William Warren Bartley III toma de la Fatal Arrogancia de Hayek, éste último concluye:

«Un observador que contemplase nuestro planeta desde algún punto del espacio quizá interpretará tal fenómeno - y las numerosas alteraciones ambientales que le acompañan-como un proceso de tipo orgánico. Pero no se trata de eso: tan grandiosa expansión es mera consecuencia de un comportamiento individual desarrollado, no por impulso de nuestras instintivas inclinaciones, sino por la asunción de los hábitos y pautas de comportamiento que de generación en generación hemos recibido.» 28

26 Véase Friedrich A. von Hayek (1990) [1988], op. cit., p. 87

27 Véase Friedrich A. von Hayek (1990) [1988], op. cit.

28 Véase William Warren Bartley III (1989), Desaparecen las fronteras. América en la Comunidad Mundial, Alocución pronunciada en la Reunión Anual de la Southwestern Social Science Association, Little Rock, Arkansas, el 30 de marzo de 1989. 


\title{
IV \\ EL PROCESO DE GLOBALIZACIÓN Y EL ANÁLISIS ECONÓMICO
}

Es una tesis ampliamente demostrada que la globalización ofrece una de las más importantes fuentes de escape a la pobreza para multitudes de pobres e indigentes en lo que generalmente se denomina el Tercer Mundo.

En este sentido señala Tomas Larsson, en su libro «La carrera hacia la Cima: la verdadera historia de la globalización»:

\begin{abstract}
«La continuidad de la pobreza en esos países, se ha basado en principio en los usos y abusos del poder político por una elite privilegiada que ha manipulado las políticas de gobierno en sus propios intereses. Abrir los mercados tanto domésticos y entre países crea oportunidades para individuos para encontrar nichos de potencial prosperidad para ellos. [...] Los mercados abiertos dan acceso a mercados de capital locales e internacionales para que emprendedores pobres en estas tierras puedan tener acceso a los recursos financieros para iniciar y operar empresas en el mercado global. Y los mercados abiertos proveen más y más baratos bienes de todo el mundo, permitiendo que aquellos con salarios inferiores en los países pobres puedan utilizar mejor sus modestos ingresos.» 29
\end{abstract}

Pero la globalización funciona, siempre que el Estado no interfiera excesivamente sobre las libertades individuales y sobre el comercio. Es el objeto de este apartado, analizar desde una perspectiva económica cada una de las interferencias que el Estado impone al proceso de globalización, o como lo definimos en la introducción a este trabajo, las interferencias que son fruto de la «ingeniería social». Debemos comprender que si ciertas sociedades han evolucionado más que otras, es sencillamente porque sus gobiernos han impuesto menores trabas al comercio, al desarrollo de la división del trabajo y en definitiva al proceso de globalización.

29 Véase Tomas Larsson (2002), The Race to the Top: The Real Story of Globalization, The Cato Store. 


\section{La ingeniería social y la globalización del intervencionismo}

$\mathrm{Al}$ respecto nos enseña Alberto Benegas Lynch (h) y Carlota Jackisch que «la aceleración de la globalización, entendida como un fenómeno tecnológico en especial en el campo de las telecomunicaciones, condujo a transformaciones significativas en los mercados de capitales mundiales, en particular durante la última década del siglo XX. Surgieron así nuevas alternativas de inversión, como los llamados "mercados emergentes", y aumentó la flexibilidad y velocidad para entrar y salir de los diversos mercados financieros [...]. El comercio exterior, en cambio, no se ha globalizado en la misma medida. A pesar de que se moderó el proteccionismo exacerbado que se viviera entre la Primera y la Segunda Guerra Mundial, el mundo aún se encuentra lejos de los estándares de libertad comercial que imperaron durante la mayor parte del siglo XIX. Conspira contra la globalización comercial, en primer lugar, una arraigada mentalidad antiliberal que ha plagado de términos militares el vocabulario del comercio internacional. Así la exportación se convierte en la "conquista de mercados", la importación pasa a ser una "invasión de productos", se deciden aumentos en los aranceles en "represalia" contra previos incrementos similares del país al que se pretende castigar, etcétera.» ${ }^{30}$

La ingeniería social de esta manera es el propósito de reconstruir íntegramente la sociedad, sin considerar que estos experimentos tienen necesariamente consecuencias no queridas y no previsibles, lo que obliga a ejercer aún más presión sobre los acontecimientos para «enderezar» la sociedad en la dirección deseada. Como señalan nuevamente Benegas Lynch y Carlota Jackisch «no es extraño que quienes asumen semejante tarea no duden en "sacrificar una generación", como era común oír en la Unión Soviética, si ese ideal lejano lo demandaba.» ${ }^{31}$

Volviendo a Hayek, esta «ingeniería social», no es otra cosa que el «racionalismo constructivista», al que podemos resumir

30 Véase Alberto Benegas Lynch (h) y Carlota Jackisch (2002), Librecambio y división de poderes, Fundación Hayek y Ediciones Lumiere SA, Buenos Aires, p. 126.

31 Véase Alberto Benegas Lynch (h) y Carlota Jackisch (2003), op. cit., p. 18. 
en los siguientes cuatro puntos: a) la creencia en que todas las instituciones que benefician a la humanidad han sido en el pasado, y deben ser en el futuro, inventadas con claro conocimiento de los efectos deseables que ellas producen; b) que ellas deben ser aprobadas y respetadas sólo en tanto y en cuanto podamos demostrar que los efectos particulares que producen en una situación particular son preferibles a los efectos que otro arreglo podría producir; c) que tenemos en nosotros el poder de diseñar nuestras instituciones de tal modo que de todos los resultados posibles, aquel que nosotros preferimos es el que resultará; d) que nuestra razón no debería nunca recurrir a herramientas «mecánicas o automáticas» cuando una consideración consciente de todos los factores hiciera preferible un resultado diferente al del proceso espontáneo. Según Hayek, de esta forma de racionalismo o constructivismo social derivan todas las formas modernas de socialismo, planificación y totalitarismo.

Esto es a lo que Ludwig von Mises, en una de sus seis conferencias en Buenos Aires denominó como intervencionismo:

«Intervencionismo significa que el gobierno no restringe sus actividades a la conservación del orden y la seguridad; quiere hacer más; interfiere en el mercado. [...] No se limita a proteger la libre actividad individual; quiere interferir en los precios, en las escalas de salarios, en las tasas de interés, en los márgenes de ganancia. Pretende restringir la supremacía del consumidor, arrogarse sus poderes, o al menos parte de ellos.» ${ }^{32}$

Es el mismo Mises quien, en su Tratado de Economía La Acción Humana, destina casi doscientas páginas a estudiar el «Mercado Intervenido», bajo la tesis de que «toda intervención del estado genera exactamente los efectos que con ella se querían evitar, y agravados».33

32 Véase Ludwig von Mises (1959), Seis conferencias en Buenos Aires, Centro de Difusión de la Economía Libre, Buenos Aires, pp. 27-28.

33 Véase Ludwig von Mises (2001) [1949], La acción humana: Tratado de Economía, 6ta Edición, Unión Editorial, Madrid, España, pp. 845-1016. 
Esta ingeniería social, creada deliberadamente, fue conceptualizada por Gabriel Zanotti como la "globalización del intervencionismo». ${ }^{34}$

Zanotti, siguiendo a Mises, lo caracterizó primero como el intervencionismo fiscal: «Todo impuesto a la renta y al capital es criticado como algo que, sencillamente, disminuye la tasa de capital existente y, con ello, disminuye los salarios reales perjudicando a los sectores de menores ingresos.»

Sigue con las medidas restrictivas de la producción: «Toda intervención del estado fijando tarifas arancelarias es rechazada como algo que, lejos de aumentar los precios y el empleo, los reducirá notablemente, además de crear un sistema económico basado en el privilegio como sistema».

Luego describe la intervención en los precios. Además de agravar los problemas inflacionarios, lo peculiar es que Mises advierte sobre la dramática consecuencia de fijar el salario (uno de los precios) por encima de su productividad, produciendo desocupación. Comienza allí su crítica a la actividad sindical de tipo fascista.

A continuación, debemos describir quizás el capítulo más importante para este trabajo, el intervencionismo monetario y crediticio: «El monopolio estatal sobre la moneda y el control de la oferta monetaria implica necesariamente inflación. La expansión crediticia implica un período artificial de expansión seguida de su inevitable efecto: la recesión.»

El capítulo concluye con otra crítica al control de cambios y al control estatal del comercio internacional. En este último aspecto, señala Zanotti, que al hablar de política monetaria internacional, el Fondo Monetario (FMI) recibe (ya en 1953) una importante crítica, y no marginal, por parte de Mises:

«El Fondo Monetario Internacional no ha conseguido aquellos objetivos que perseguían sus patrocinadores. Mucho en verdad se habla y se discute con motivo de las reuniones anuales que el mismo celebra; en ellas, a veces, incluso se puede escuchar pertinentes observaciones y acertadas críticas de la política monetaria que hoy

34 Véase Gabriel J. Zaontti (2002), La Globalización frente a la Escuela Austriaca de Economía, Management Herald, 5 de diciembre de 2002. 
siguen los gobiernos y sus bancos de emisión. El Fondo sigue, sin embargo, operando con dichos bancos y gobiernos, y considera que su fin primordial es auxiliar a unos y a otros para que puedan mantener tipos de cambio a todas luces arbitrarios, dada la expansión monetaria que de continuo practican. Las normas monetarias que aplica y recomienda son sustancialmente aquellas a las que, sin éxito, han recurrido siempre, en casos similares, todos los arbitristas monetarios. La errónea política monetaria que hoy impera por doquier sigue adelante sin preocuparse para nada ni del Fondo Monetario ni de los acuerdos adoptados en Bretton Woods.»35

A paso siguiente, describe otro capítulo sobre la política confiscatoria, prediciendo su obvio efecto: «descapitalización, mayor pobreza y subdesarrollo».

Concluye finalmente con la crítica al intervencionismo sindical, «a esa unión fascista entre sindicatos y estado que concluye en la más amplia y devastadora desocupación, a lo cual se sigue una crítica a la mentalidad belicista como excusa para la intervención del estado».

Por una cuestión de espacio, es imposible aquí tratar cada una de las políticas intervencionistas que comentamos. Por ello seleccionaremos a continuación algunas políticas que restringen el proceso de globalización, impidiendo que la erradicación de la pobreza sea un sueño cumplido, aún en los países del Tercer Mundo. Estas políticas las agruparemos en dos conjuntos, aquellas relativas al comercio internacional y aquellas relativas a la moneda.

\section{La ingeniería social en el ámbito del comercio exterior}

No es casual que en paralelo con el primer proceso de aceleración de la globalización haya surgido en el mundo de las ideas, un movimiento que intentara restringirlo. Después de todo, la globalización no se introduce pasivamente en la vida social, sino que genera fuertes cambios que muchas veces son difíciles de

35 Véase «La Reconstrucción Monetaria», en Ludwig von Mises (1997) [1953], La teoría del dinero y del crédito, Unión Editorial, Madrid, España. 
sortear. Al respecto, cabe hacer una nueva referencia a Mises, en una de sus conferencias en Buenos Aires, esta vez, sobre la Revolución Industrial:

«El sistema fabril evolucionó en continua lucha con innumerables obstáculos. Debió combatir prejuicios populares, antiguas costumbres establecidas, normas y reglamentaciones legales restrictivas; la animosidad de las autoridades, los intereses creados de grupos privilegiados. Los bienes de capital de las firmas individuales eran insuficientes y la obtención de créditos hacíase extraordinariamente difícil y costosa. Se carecía de experiencia tecnológica y comercial. La mayoría de los propietarios de fábricas fracasaron; los que triunfaron fueron relativamente pocos. A veces las ganancias eran considerables, pero lo mismo sucedía con las pérdidas, y transcurrieron muchas décadas hasta que la práctica común de reinvertir la mayor parte de las ganancias llegó a producir la acumulación de un capital adecuado para la conducción de los negocios en escala más amplia.» ${ }^{36}$

El siglo XVI fue acompañado, según comentamos, por la primera aceleración del proceso de globalización, y en consecuencia con la primera intensificación de la división del trabajo a nivel mundial. La expansión naval de las potencias europeas permitió la colonización, conquista y desarrollo de intercambios comerciales con escalas nunca vistas hasta entonces. Las consecuentes transformaciones en todos los ámbitos de la vida social fueron acompañadas entonces con el nacimiento de lo que hoy se conoce como la «doctrina mercantilista».

\section{a) La Doctrina Mercantilista como precursora del Keynesianismo}

Los defensores de este sistema no eran estudiosos de la economía sino que se consideraban «hombres prácticos de negocios», entre quienes se contaban T. Milles, W. Petty, T. Mun, G.D. Malynes,

36 Véase Ludwig von Mises (1959), op. cit., p. 11. 
M. Montaigne, J. B. Colbert, E. Misselden y W. Potter. Básicamente, explica Benegas Lynch (h) en sus Fundamentos de Análisis Económico, «el mercantilismo sostenía que la riqueza de una nación consiste en la cantidad de dinero (en esa época metálico) que acumulara. Así se afirmaba que convenía estimular las exportaciones y, simultáneamente, limitar las importaciones a través de derechos arancelarios. Se introdujeron controles cambiarios, se requerían licencias para comerciar, carnets para agremiarse, se otorgaban privilegios para el establecimiento de monopolios, se incrementaban impuestos para alimentar a la creciente burocracia, se imponían controles de precios, subsidios y controles estatales de toda naturaleza». ${ }^{37}$

Quizás el más destacado de los mercantilista, haya sido Colbert, quien diseñó controles meticulosos y minuciosos para la producción y la comercialización. Un ejemplo lo constituye su objetivo de «uniformidad nacional de los artículos elaborados», para lo cual estableció una reglamentación (vigente a través de decretos para el período 1666-1730), que se hallaba recopilada en cuatro volúmenes, totalizando 2.100 páginas. A aquellos siguieron luego, otros tres suplementos aparecidos posteriormente, casi tan substanciales como los anteriores. ${ }^{38}$

Los mercantilistas fueron los precursores del keynesianismo, y por tanto de muchas de las políticas económicas que aún aplican los diversos gobiernos. Esto se puede observar por ejemplo

37 Véase Alberto Benegas Lynch (1994a), Fundamentos de Análisis Económico, Abeledo-Perrot, Buenos Aires, p. 394.

38 R. Lekachman en la «Historia de las doctrinas económicas», Ed. V. Lerú, 1959, pp. 4-6, comenta que «el reglamento sobre tejidos comprendía 59 artículos. Otros dos contenían respectivamente 62 y 98 artículos y el más grande llegaba a la sorprendente suma de 317 artículos. [...] La reglamentación disponía, según el curso de la producción, desde la materia prima hasta la obtención del producto elaborado. Las especificaciones cubrían toda la gama del manejo correcto de los materiales esenciales y cada una de las etapas sucesivas. El hilado y el teñido recibían especial atención. Las mediciones se hacían con precisión. Bastará un simple artículo para mostrar la magnitud de lo expresado: una fábrica de Dijon debía poner en los peines $13 / 4 \mathrm{~m}$. de ancho, una urdimbre debía contener 1.408 hebras, 44 por $32 \mathrm{~cm}$., incluyendo el orillo, de modo que cuando el tejido llegara a la tejeduría midiera exactamente 1 metro. Los reglamentos distinguían tres categorías de tintoreros: los que se encargaban de piezas de colores genuinos, los que debían darles otro color y los que trataban las sedas, lanas e hilos. Todos estos detalles continuaban en una serie interminable e infinita.» 
en el capítulo 23 de su Teoría General, al que tituló «Notas sobre el mercantilismo, las leyes sobre la usura, el dinero sellado y las teorías del subconsumo». Allí Keynes explica:

«Por espacio de unos doscientos años tanto los teóricos de la economía como los hombres prácticos no dudaron que una balanza de comercio favorable tiene particulares ventajas para un país y graves peligros la adversa, especialmente si se traduce en eflujo de los metales preciosos; pero durante los últimos cien años se ha presentado una notable divergencia de opinión. La mayoría de los estadistas y los hombres prácticos en casi todos los países, y cerca de la mitad de ellos aun en Gran Bretaña, cuna del punto de vista opuesto, han permanecido fieles a la antigua doctrina; en tanto que casi todos los economistas teóricos han afirmado que la preocupación por tales problemas carece de base, salvo si se adopta un punto de vista muy estrecho, ya que el mecanismo del comercio exterior es de ajuste automático y los intentos de dirigirlo no sólo son fútiles, sino que empobrecen a quienes los practican, porque anulan las ventajas de la división internacional del trabajo. Será conveniente, de acuerdo con la tradición, llamar a la vieja opinión mercantilismo y a la nueva librecambio, aunque estos términos deben interpretarse con referencia al contexto, pues cada uno de ellos tiene un significado amplio y otro restringido.» ${ }^{39}$

Nada más alejado de la realidad. Keynes evidentemente no comprendió los aportes bajo las leyes de «ventaja absoluta» $\mathrm{y}$ «ventaja comparativa» de Adam Smith y David Ricardo, respectivamente, que luego se sintetizaron en la «Ley de Asociación» de Ludwig von Mises. Tampoco comprendió la importancia de la división internacional del trabajo (luego ampliada por Hayek bajo la «división del conocimiento») sobre la que Keynes también escribió:

«Las ventajas de la división internacional del trabajo son reales y sustanciales, aun cuando la escuela clásica las haya exagerado grandemente. El hecho de que las ventajas derivadas de una

39 Véase John Maynard Keynes (1936), Teoría general de la ocupación, el interés y el dinero, Fondo de Cultura Económica, Serie de Economía, p. 279. 
balanza favorable para nuestro propio país puedan suponerse desventajas iguales para algún otro (cosa de la cual los mercantilistas se daban cuenta perfecta) no sólo significa que es necesaria una gran moderación, de manera que un país no asegure para sí mismo una parte mayor que la justa y razonable de las existencias de metales preciosos, sino también que una política inmoderada puede llevar a una competencia internacional insensata por una balanza favorable que dañe a todos por igual.» 40

El desconcierto de Keynes sin duda es grande y aquí brevemente intentaremos ilustrar las razones de su confusión. Keynes, en la segunda oración del último párrafo citado, explica que las ventajas obtenidas por el país que obtiene la «balanza favorable» implica una «desventaja» en aquel país que obtiene un déficit comercial. Esto es lo que ha llevado a Keynes a afirmar, siguiendo a la doctrina mercantilista, que la política recomendable en materia de comercio exterior es estimular las exportaciones, pero a su vez, inhibir las importaciones. Para ello, es necesario implementar toda clase de artilugios que pasamos a estudiar.

\section{b) No hay diferencia entre el comercio local y el internacional}

En primer lugar, debemos comprender que el comercio internacional en nada se diferencia del comercio que se lleva a cabo dentro de un mismo país. Benegas Lynch (h) explica que «océanos, ríos, montañas o cualquier frontera política convencional en nada cambian los principios y las relaciones teleológicas inherentes a la economía. La nación —como veremos más adelanteno comercia, intercambian específicos individuos de modo directo o indirectamente a través de asociaciones de diversa naturaleza. El tratamiento por separado del comercio exterior diferenciándolo del comercio interior se debe a la gran cantidad de falacias tejidas en torno a las relaciones internacionales.» 41

40 Véase John Maynard Keynes (1936), op. cit., p. 300.

41 Véase Alberto Benegas Lynch (1994a), op. cit., p. 393. 
Lo que en el comercio local llamamos compra y venta, en comercio internacional lo denominamos importaciones y exportaciones. ¿Es acaso la compra más beneficiosa que la venta? La pregunta no tiene sentido. Compra y venta, importación y exportación son tan sólo dos caras de la misma moneda. Vendemos para luego poder comprar. Exportamos para luego poder importar. No tiene sentido vender o exportar permanentemente, acumulando dinero (o metálico) si en ningún momento posterior voy a intentar utilizar lo recaudado para comprar o importar algún bien o servicio.

En todo caso, nada habría más favorable para la sociedad de un determinado país que el poder importar sin necesidad de exportar. Lamentablemente, esta situación no resulta posible puesto que implica que el resto del mundo le está regalando cosas al país en cuestión.

A su vez, debemos recordar que en toda compra y venta, y de la misma manera, en toda importación y exportación, la implicación fundamental es que las dos partes que intercambian resultan beneficiadas de la operación. Hemos observado en el apartado anterior cómo la necesidad de comercio llevó al progreso a las sociedades a lo largo de la historia. El proceso de globalización justamente enriquece a los pueblos y erradica la pobreza porque estimula y facilita los intercambios entre personas de las más varias culturas y con muy diferentes costumbres. En toda operación voluntaria de intercambio sólo hay ganadores. No es cierto como afirma Keynes que mientras una parte gana la otra pierde.

A su vez, debemos comprender que la balanza comercial es sólo una parte de la balanza de pagos. La balanza comercial incluye las llamadas partidas visibles (o transacciones de bienes), mientras que la balanza de capital, incluye los movimientos de capital o partidas invisibles. Ambas balanzas, juntas, determinan la balanza de pagos.

Si tomamos por caso a Estados Unidos, probablemente como la nación más poderosa del mundo, observaremos que la balanza comercial experimenta el déficit más grande que la historia económica haya registrado jamás. ¿Qué es lo que permite a Norteamérica importar productos y acumular déficits tan grandes año tras año? Y la respuesta la debemos encontrar en la balanza de capitales, que evidencia un flujo de capitales en forma 
de inversión extranjera directa, que tampoco se ha visto en la historia económica mundial.

Jacques Rueff era sumamente ilustrativo respecto de la mejor política a adoptar ante los resultados de la balanza de pagos:

«El deber de los gobiernos es permanecer ciegos frente a las estadísticas del comercio exterior, nunca preocuparse de ellas, y nunca adoptar políticas para alterarlas [...] si tuviera que decidirlo no dudaría en recomendar la eliminación de las estadísticas de comercio exterior debido al daño que han hecho en el pasado, el daño que siguen haciendo y, temo, que continuarán haciendo en el futuro.» ${ }^{42}$

Son estas falacias las que aun hoy abundan en los medios de comunicación bajo frases como "vivir con lo nuestro», "controlar la entrada y salida de capitales», «exportar lo más posible», «importar lo menos posible», «acumular reservas como objeto de la política económica», «cerrar la economía para que surja una industria fuerte que pueda competir en algún momento futuro, pero no determinado, con el mundo», «evitar el ingreso de capital golondrina», «prohibir por ley el retiro de capitales, sea en forma de remesas o dividendos», "garantizar que el capital no se retire antes del año», etc. En resumen, un claro NO, al capital extranjero.

\section{c) La devaluación de la moneda local}

Una de las políticas públicas más observadas en la actualidad para estimular las exportaciones e inhibir las importaciones se encuentra representada con la devaluación de la moneda. Mises lo explica perfectamente:

«Puesto que los sindicatos rechazaban toda posibilidad de reajustar los salarios al valor de la moneda y al nivel de los precios, lo que procedía era acomodar uno y otro a los emolumentos coactivamente impuestos. No es - decía el gobierno-que las rentas laborales sean demasiado altas; sucede que la moneda nacional

42 Véase Jacques Rueff (1967), Balance of payments, Macmillan, p. 128. 
está encarecida con respecto al oro y las divisas extranjeras, por lo que debe procederse a reajustar esta última relación. La devaluación monetaria iba a ser la panacea universal.

Los objetivos de la devaluación eran:

1. Mantener los salarios nominales y aun incluso poder aumentarlos mientras los reales más bien se reducían.

2. Incrementar en términos de moneda nacional los precios, especialmente los de los productos agrícolas, o al menos contener su descenso.

3. Favorecer a los deudores a costa de los acreedores.

4. Fomentar las exportaciones y reducir las importaciones.

5. Atraer el turismo y hacer más gravoso para los ciudadanos del país - siempre hablando en términos de moneda nacionalel desplazamiento al extranjero.

Pero ni los gobernantes ni aquellos intelectuales que defendían esa política se atrevieron a proclamar lealmente que lo que en verdad se pretendía con la devaluación era reducir los salarios reales.» ${ }^{43}$

Y agrega Mises: «Preferían decir que la devaluación no tenía más objeto que combatir un supuesto "desequilibrio estructural" entre el "nivel" de los precios nacionales y el "nivel" de los internacionales. Reconocían que era necesario reducir los costes nacionales de producción; pero silenciaban cuidadosamente que uno de los costes que pensaban rebajar eran los salarios reales y otro lo pagado por intereses y por principal en créditos a largo plazo.»

\section{d) El control de cambios}

Otra política la representa el control de cambios. Benegas Lynch (h) explica que "generalmente, a través del control de cambios se pretende ocultar los efectos de la inflación sobre la paridad

43 Véase Ludwig von Mises (2001) [1949], op. cit., pp. 931-932. 
$\mathrm{y}$, a su vez, sobre los precios internos.» ${ }^{44}$ Supongamos entonces que se sobrevalúa la moneda local en términos de la extranjera.

Esta medida hace que se contraigan las exportaciones, puesto que así se disminuye el precio del producto exportado. A su vez, estimula la importación debido a que la divisa extranjera resulta artificialmente más barata. Ahora, si el mercado permaneciera libre de controles, al aumentar las importaciones la demanda por divisas extranjeras hubiera hecho que éstas subieran de precio con lo cual se hubieran frenado las importaciones y se hubieran estimulado las exportaciones. Sin embargo, como el tipo de cambio se mantuvo fijo a la paridad oficial, el importador continúa comprando en el exterior puesto que la divisa extranjera resulta artificialmente barata. Esta salida artificial de divisas, junto con la contracción también artificial en las entradas de divisas es lo que conduce a los referidos desajustes en el balance de pagos.

Siguiendo la tesis de Mises, no es extraño señalar que desde el punto de vista de la doctrina mercantilista, el deseo de aumentar las exportaciones y disminuir las importaciones se traduce en los efectos opuestos debido al control de cambios.

\section{e) La des-protección arancelaria}

Una tercera política ampliamente difundida y aplicada en la actualidad, la constituye la protección arancelaria. La misma busca impedir, limitar o encarecer las importaciones, cerrando las fronteras, de manera que el país se autoabastezca, adoptando de ese modo la autarquía como sistema. La autarquía significa el nocomercio. Si un individuo lo adoptara, debería renunciar a todas sus compras habituales y fabricar él mismo sus propios bienes, lo que implicaría disminuir enormemente su nivel de vida.

Pero tal sistema, que a nivel individual sería considerado una locura, es lo que se pone como ideal a nivel internacional. En efecto, el objetivo que buscan quienes proponen esta idea de

44 Véase Alberto Benegas Lynch (h) (1994), op. cit., p. 404. 
«autoabastecimiento», es que el país ya no «dependa» del exterior, a la vez que estimularía la generación de empleo local.

Por supuesto, que en este caso el nivel de vida no disminuye tanto como en la autarquía individual, puesto que uno acepta el comercio con otros miles o millones de individuos dentro del país, pero sin duda, el coste de oportunidad de no operar con el exterior es enorme, lo que se traduce en compra de bienes y servicios a precios mayores y a la vez, en una limitación a consumir aquellos bienes que sólo pueden producirse internamente.

Además, el arancel es, en efecto, negativo en cuanto a tal fin. Imponer un arancel significa derivar la producción de una región en la que la productividad por unidad de inversión es mayor hacia otra región donde la productividad por unidad de inversión es menor, con la consecuente baja en la productividad global.

Observemos un claro ejemplo para ilustrar este argumento y que posteriormente nos servirá a los efectos de atender a un problema real que hoy se vive tanto en los países que integran la Unión Europea como en los Estados Unidos: Imaginemos un país A, que por estar situado en una zona montañosa importa carne del país $B$, que tiene abundante ganado vacuno. Pero el país A quiere autoabastecerse de ganado vacuno. A tal efecto impone un arancel a la importación de tal manera que se haga imposible comprarlo. El país A, luego, tratará de producir ganado vacuno, cosa para lo cual no tiene aptitud natural. Recursos que antes se empleaban en la fabricación de bienes para los cuales se tenía capacidad productiva, serán forzosamente desviados a la fabricación de un bien que requerirá - en esa zona montañosa- costes enormes de producción. No sólo se tendrá en ese caso ganado de peor calidad y mayor precio sino que los bienes que antes el país fabricaba serán también ahora desatendidos, al extraérseles gran cantidad de recursos que se empleaban en su fabricación para derivarlos al nuevo bien que se está intentando fabricar. El proceso de desvío de recursos se produce al tener que pagar el consumidor más caro el bien que antes se importaba, disponiendo de menos recursos que antes empleaba en la compra de bienes nacionales.

Vemos entonces, cómo carece de sentido el argumento de que imponer barreras a la importación y así autoabastecernos aumenta las fuentes de trabajo, puesto que los factores de producción 
aquí no se multiplican hacia el nuevo sector del que antes se importaba, sino que necesariamente, se deberá desatender el sector que antes era más rentable. Esta re-asignación de recursos por supuesto no es eficiente y empobrece a la sociedad.

Cabe sin embargo una última aclaración. Ningún país de los que hoy aplican esta política proteccionista lo hace en un 100\%, esto es, ningún país aplica aranceles para encarecer la importación de todos los productos, sino que se seleccionan sólo algunos de forma arbitraria, o que se consideran estratégicos para el país en cuestión. Pero, ¿qué motiva esta política? Adam Smith, hace ya 230 años contestaba correctamente esta pregunta:

«Haciendo uso de restricciones - mediante elevados derechos de aduanas, o prohibiendo en absoluto la introducción de los géneros extranjeros que se pueden producir en el país- se asegura un cierto monopolio del mercado interior a la industria nacional consagrada a producir esos artículos.»45

Esta política de favorecer la industria nacional es sin duda en perjuicio de los consumidores que ahora deberán pagar precios mayores por los mismos bienes y servicios que antes consumían a un precio menor. El gobierno con esta política favorece a pseudo-empresarios otorgándoles un monopolio sobre el cual operarán tranquilamente, en ausencia de competencia exterior.

\section{f) El argumento de la industria incipiente}

Algunos economistas comprenden parcialmente las explicaciones presentadas en el epígrafe anterior, argumentando (tal como lo hacía Keynes), que conviene ser moderados en la política exterior. Si bien aceptan que no pueden aplicar aranceles eternamente para no provocar los problemas señalados, argumentan que generalmente se imponen barreras aduaneras para proteger

45 Véase Adam Smith (1776), Investigación sobre la naturaleza y causas de la riqueza de las naciones, Fondo de Cultura Económica, Serie de Economía, p. 399. 
la industria incipiente hasta que esta sea lo suficientemente fuerte para poder competir.

Pareciera que se razona de distinta manera cuando se trata de comerciar dentro de la nación, dado que a pocos se les ocurriría esgrimir allí este argumento para otorgar privilegios a los competidores. Pero cuando se trata de comercio internacional, entre otras cosas, equivocadamente se supone que los competidores de otros países quedarán estáticos esperando que aquella «industria nacional» se desarrolle adecuadamente para proseguir la competencia. Debe señalarse, además, que mientras dure la «protección a los incipientes» (que generalmente se hace perpetua) la comunidad está destinando innecesariamente más recursos por unidad de producto, lo cual implica dilapidación del siempre escaso capital.

A la vez, debemos argumentar que aun cuando la protección arancelaria se elimine, la industria incipiente local sigue aun siendo incipiente, dado que la ausencia de competencia evitó un desarrollo vigoroso de la industria.

Debemos afirmar entonces que la única forma de que la «industria nacional e incipiente» se desarrolle es operando libremente y compitiendo. Y esto no implica únicamente eliminar aranceles, sino también eliminar controles de cambio y eliminando toda legislación diferenciada para el inversor extranjero. Es fundamental que la igualdad ante la ley se cumpla tanto a nivel local como a nivel internacional. No se le debe exigir al capital «extranjero» ningún requisito que no se le exija al inversor local. Sólo así se garantiza la competencia, se elimina la dilapidación de capital y la industria local se desarrolla, generando empleo y un crecimiento sostenible.

\section{g) Reciprocidad de otras naciones}

Un nuevo argumento de quienes se resisten a aplicar el librecambio lo constituye el hecho de considerar que todos los efectos positivos se anulan si no existe reciprocidad de otras naciones. En otras palabras, sólo es posible practicar el libre comercio si lo practican todos los países del mundo. 
Pero esto representa una nueva falacia. Si todo el mundo practica la autarquía entonces será indiferente aplicar políticas librecambistas o proteccionistas, puesto que no habrá intercambio.

Ahora, hemos explicado previamente que el objeto de la exportación es la importación, y viceversa, lo que implica que si existe alguien que le compre a ese país o alguien invierta sus recursos en ese país éste podrá, a su vez, adquirir productos del exterior. Si esto último lo lleva a cabo sin aranceles habrá sacado partida de la cooperación social y habrá evitado, en esa medida, los inconvenientes del régimen autárquico que previamente describimos.

\section{h) Los Tratados de Integración Regional}

Este es un punto que debemos tratar cuidadosamente, puesto que ha generado mucha confusión. Observamos actualmente que los distintos países del mundo se están asociando comercialmente con sus países vecinos a través de tratados regionales de libre comercio. Tal es el caso de los países de la Unión Europea, o en América, del Nafta, el Mercosur, o el potencial Alca sobre el cual aún no hubo acuerdo.

Considerando el estado de autarquía que el mundo experimentaba tras la primera y la segunda guerra mundial, podríamos argumentar que estos acuerdos de integración han sido positivos para los países miembros puesto que los sacaron del total aislamiento para comenzar a comercializar productos con sus vecinos. En la Unión Europea, fue esta integración la que logró por ejemplo establecer en Irlanda un proceso de crecimiento económico que le permitió disminuir su deuda externa desde un $160 \%$ del PIB a tan sólo un $40 \%$. Irlanda transformó completamente su economía, al pasar de ser una sencilla economía agraria, a recibir más del $50 \%$ de las inversiones extranjeras directas norteamericanas, para destinarlas a la industria de Internet, guiados por las bajísimas tasas impositivas, en relación con sus vecinos Francia y Alemania. A su vez, el salario real per cápita, que hace quince años estaba muy por debajo del promedio de 
la Unión Europea, hoy ya supera con creces al de Inglaterra y sigue en ascenso.

Sin embargo, debemos ser críticos de tales asociaciones de libre-comercio. El argumento es que estos tratados de integración regional implican desviar el comercio de sus cauces naturales, al incentivar las transacciones intrazonales con los países miembros en perjuicio del resto del mundo. No es extraño que en estos procesos los aranceles extra-zonales resulten más elevados que los vigentes antes de la integración regional.

Al respecto, podemos citar a Martín Simonetta, quien nos ilustra respecto del caso de la Argentina y el Mercosur:

«La pertenencia al Mercosur vedó a la Argentina la posibilidad de negociar acuerdos comerciales en forma individual y la obligó a hacerlo en bloque. Los resultados fueron claros: los acuerdos firmados por este bloque proteccionista fueron mínimos y mantuvieron fuera del mega mercado cautivo a países de mayor productividad relativa tales como Estados Unidos, la Unión Europea o los países asiáticos.» ${ }^{46}$

En el mismo sentido, Benegas Lynch (h) presenta un nuevo argumento: «Es interesante detenerse en la lectura de los documentos de las integraciones económicas regionales de mayor relevancia. Allí se estipulan ciertas cosas como que si el país $b$ le compra productos al país a éste le hará ciertas "concesiones". Las concesiones consisten en que $a$ reduce los derechos aduaneros para comprarle a $b$ a un menor precio. Si reducir derechos aduaneros es una concesión, una gracia, un favor, quiere decir que no se han entendido las ventajas de la integración ni del librecambio.» ${ }^{47}$

Hoy en la Argentina, los defensores de un Mercosur, afirman que conviene asociarse a países con características similares, pero precisamente las ventajas surgen en la medida en que los países integrados sean distintos. El intercambio no tiene sentido

46 Véase Martín Simonetta (2002), Bases para la integración al mundo de la economía argentina, Soluciones de Políticas Públicas, Fundación Atlas, julio 2002.

47 Véase Alberto Benegas Lynch (h) (1994), op. cit., p. 405. 
y no se lleva a cabo entre individuos o países que tienen las mismas habilidades y producen las mismas cosas. Si se comprende la ventaja de la integración ésta debiera realizarse con el mundo en su totalidad, en lugar de circunscribir la ventaja a determinada zona.

\section{La ingeniería social y la moneda}

Sería desatinado no tratar aquí la ingeniería social en lo relativo a la moneda, cuando observamos en el mundo permanentes crisis monetarias, financieras y cambiarias, con efectos contagio que deprimen varias economías de un plumazo, y cuya causa muchas veces se adjudica a la globalización financiera. Este punto sin duda será fundamental cuando nos adentremos en la pregunta ¿quién ordena el comercio internacional?.

\section{a) Crisis monetarias, financieras y cambiarias alrededor del mundo}

Los últimos quince años han sido desastrosos en materia financiera, monetaria y cambiaria tanto para países en vías de desarrollo como para los países desarrollados.

Comenzando por Norteamérica, Estados Unidos ha experimentado una burbuja bursátil que ha llevado en 2002 a una caída en el valor de las acciones equivalente a los 7 billones de dólares, el equivalente en ese momento al PIB de toda la Unión Europea o al 80\% del PIB de Estados Unidos. La economía norteamericana se encuentra terriblemente endeudada por sus acumulados déficit comerciales y fiscales. Si bien ha experimentado importantes mejoras de productividad y aunque presenta niveles de crecimiento de PIB importantes, ningún analista puede asegurar que la depresión ha quedado atrás.

En Centro América, con México a la cabeza, si bien el ingreso al Nafta le ha permitido abrir su economía y salir del aislamiento, el «efecto tequila» de 1995 ha demostrado la fragilidad del sistema financiero y su fuerte dependencia a los movimientos en la tasa de interés de Estados Unidos. 
En América del Sur, la crisis de Brasil primero y la de Argentina después, ambas con devaluación, se han propagado por todo el Mercosur y han devastado sus economías. La liberalización de mercados chilena podemos decir que ha sido la excepción a la regla.

En Europa Occidental, las potencias alemana y francesa se encuentran en un estancamiento importante de sus economías y con un fuerte riesgo por entrar en recesión. España por su parte, vive una burbuja inmobiliaria sin precedentes.

En Europa Oriental, luego de desterrar completamente el socialismo, comienzan a recuperarse las economías, pero el proceso es demasiado lento. No está demás mencionar la crisis rusa de 1998 que afectó a todos los países emergentes y que significó para los inversores extranjeros la pérdida del 70 u $80 \%$ del capital invertido en títulos de deuda interna.

En Asia finalmente debemos hablar del largo estancamiento que experimenta la economía japonesa desde 1989. Según afirmó Ronald McKinnon, profesor de economía internacional de la Universidad de Standford de los Estados Unidos, «...la incapacidad para diagnosticar el prolongado hundimiento económico de Japón, con la inversión privada y el consumo languideciendo y el sistema bancario en perpetua crisis, se ha convertido en $\mathrm{el}$ gran fracaso de la macroeconomía moderna».

Por supuesto cada crisis económica tiene sus particularidades, sin embargo nos animaremos aquí a dar una explicación común a todas ellas.

\section{b) La Teoría Austriaca del Ciclo Económico}

La Teoría Austriaca del Ciclo Económico es quizás la contribución más importante que Ludwig von Mises aportara a la Ciencia Económica. ${ }^{48}$ Fue Mises quien creó el Instituto Austriaco de Coyuntura Económica, colocando al frente como Director a Friedrich A. von Hayek, convirtiéndose luego en el único Instituto capaz de

48 Véase el Estudio Preliminar escrito por Jesús Huerta de Soto, a la última edición española del Tratado de Economía de Mises La acción humana, donde presenta las seis aportaciones más importantes que a su juicio elaboró el autor. 
predecir el advenimiento de la Gran Depresión de 1929, como inexorable resultado de los desmanes monetarios y crediticios de los «felices» años veinte del siglo pasado que siguieron a la Primer Guerra Mundial. ${ }^{49}$

En efecto, Mises, aplicando las teorías monetarias de la $\mathrm{Cu}$ rrency School a las teorías subjetivistas del capital e interés de Eugen Böhm von Bawerk, se dio cuenta de que la creación expansiva de créditos sin respaldo de ahorro efectivo (medios fiduciarios) a que daba lugar tanto la emisión monetaria como el sistema bancario basado en un coeficiente de reserva fraccionaria dirigido por un banco central, no sólo generaba un crecimiento cíclico y descontrolado de la oferta monetaria, sino que también, al plasmarse en la creación de créditos a tipos de interés artificialmente reducidos, inevitablemente daba lugar a un «alargamiento» ficticio e insostenible de los procesos productivos, que tendían así a hacerse de forma indebida excesivamente intensivos en capital. La amplificación de todo proceso inflacionario mediante la expansión crediticia, tarde o temprano de manera espontánea e inexorable, habrá de revertirse, dando lugar a una crisis o recesión económica en la que los errores inducidos en la inversión se pondrán de manifiesto y surgirán el paro masivo y la necesidad de liquidar y reasignar todos los recursos erróneamente invertidos. ${ }^{50}$

Esto es precisamente lo que ocurre en el mundo de hoy. Si tomamos por caso la crisis japonesa, Benjamín Powell explica en un trabajo sobre la depresión de esta economía que luego de tres décadas de «milagro» de crecimiento económico posterior a la Segunda Guerra Mundial, la economía de Japón se oscureció bruscamente en 1990 y ha permanecido paralizada desde

49 Véase Mark Skousen (1993), «Who predicted the 1929 Crash?», incluído en The Meaning of Ludwig von Mises, Jeffrey M. Herbener (ed.), Kluwer Academic Publishers, Amsterdam, pp. 247-284.

${ }^{50}$ Huerta de Soto, ibidem. El desarrollo de Mises de la teoría del ciclo se encuentra estudiado con detalle en los capítulos XX y XXXI de su Tratado de Economía. A su vez, si el lector se encuentra interesado en el tema de estudio puede acceder al ensayo del autor de este trabajo, titulado «Formación de Capital y Ciclos Económicos, una introducción al análisis macroeconómico», Libertas N. 43, ESEADE, Buenos Aires, Octubre de 2005. 
entonces. El autor examina en dicho trabajo las condiciones económicas de Japón desde 1989 y luego estudia las distintas conclusiones a las que llegan los analistas keynesianos, monetaristas y austriacos. Su conclusión final es que Japón ha experimentado un "ciclo económico austriaco", dado por una expansión monetaria inicial por parte del Banco Central. Las sucesivas intervenciones evitaron el reajuste y por ello la economía se ve imposibilitada de salir definitivamente de la recesión. Sugiere que para una recuperación de la economía japonesa se necesita dejar de intervenir, permitiendo que el proceso de mercado logre compatibilizar la estructura intertemporal de la producción existente con las preferencias de los consumidores. ${ }^{51}$

Pero retomemos las palabras de Ronald Mc Kinnon: la crisis japonesa sería «el gran fracaso de la macroeconomía moderna». Por supuesto podríamos extender estas palabras hacia el caso norteamericano y europeo, pero también a los casos de los países en vías de desarrollo. La macroeconomía moderna no estudia otra cosa que distintas formas de manipular la tasa de interés, controlar el tipo de cambio y disminuir o incrementar la oferta monetaria según criterios aleatorios del presidente de turno del Banco Central.

Tomemos un nuevo ejemplo: la economía norteamericana. Alan Greenspan con su intento de recuperar la economía ha manipulado la tasa de interés hasta llevarla al nivel más bajo de la historia. Incluso hay analistas que aseguraron que la tasa de interés real en Estados Unidos era negativa si se consideraba que la tasa de interés nominal era menor que la tasa de inflación.

El proceso de globalización traducido en los enormes incrementos de productividad provocados por los avances de Internet y la comunicación le han dado un respiro a la economía norteamericana. Pero el nivel de endeudamiento tanto en materia fiscal como comercial y fundamentalmente las continuas manipulaciones en materia monetaria y cambiaria posiblemente se vean reflejados en una importante depresión que lamentablemente azotaría también a casi todas las economías del mundo.

51 Véase, Benjamín Powell, Explaining Japan Recession, Mises Institute. Otro ensayo sobre la crisis de Japón es el de Christopher Mayer titulado «Japan's Bust: An Austrian Critique of the Fed's Explanation». 
Podríamos sugerir que todas las crisis nombradas no son más que una sola crisis. La crisis generada por la reserva federal y cada uno de los bancos centrales que manipulan los precios, la tasa de interés y la cantidad de dinero que circula en una economía.

\section{Segunda Conclusión}

El presente apartado intentó complementar el presentado en el primer capítulo. Allí el análisis económico hayekiano nos permitió comprender cómo funciona el proceso de mercado, qué rol juega el sistema de precios, cómo la sociedad puede utilizar el conocimiento disperso y limitado en la sociedad, la importancia que la función empresarial tiene con su permanente búsqueda de oportunidades y en definitiva lo beneficioso que el proceso de globalización puede ser para una sociedad, creando un orden extenso que permita a la sociedad progresar permanentemente, enriqueciendo a sus integrantes, y erradicando la pobreza.

De dicho análisis debemos advertir sin embargo, que cualquier intento de planificación global lo des-ordenaría, paradójicamente, al des-articular algo clave en cualquier orden espontáneo: «el sistema de información por medio del cual se sintetiza la poca información dispersa que hay».

Gabriel Zanotti, en su «Introducción Filosófica al pensamiento de F.A. von Hayek» nos enseña que «esos sintetizadores de información dispersa son los precios. Esto presupone dos cosas más. Un presupuesto institucional, la propiedad y la libre entrada, en cuyo seno se forman los precios, y un presupuesto antropológico: que habrá aprendizaje, por parte de algunos, tal que compensará el conocimiento limitado.» ${ }^{52}$

En pocas palabras, para Hayek el proceso de mercado es un proceso de descubrimiento, y funciona mejor cuando los sintetizadores de información no sufren ninguna distorsión.

Cada una de las políticas que presentamos en los dos últimos epígrafes, justamente vienen a interferir en estos sintetizadores

52 Véase Gabriel J. Zanotti (1993), «Introducción Filosófica al Pensamiento de F.A. von Hayek», Estudios Públicos N. 50, Chile, otoño 1993. 
de información, lo que restringe, pero no elimina la función empresarial.

La expansión monetaria artificial, la distorsionada tasa de interés, los controles de precios, los aranceles, el control de cambios, los subsidios a la industria local, y todos los artilugios que el gobierno decida implementar para desarrollar su economía distorsionan los precios relativos, provocan mala-asignación de recursos y muchas veces estimulan errores en la actividad empresaria. Los empresarios, ante semejante debilidad en las instituciones muchas veces invierten a riesgo de perderlo todo, y muchas otras, directamente deciden no invertir, lo que en definitiva restringe completamente la función empresarial.

\section{$\mathrm{V}$}

\section{LA GLOBALIZACIÓN Y EL ORDEN INTERNACIONAL}

La última aceleración del proceso de globalización ha generado un nuevo orden internacional que constituye un importante desafío para la arrogancia de quienes quieren siempre imponer un orden a la sociedad. Los diversos gobiernos no encuentran la forma de controlar el comercio vía Internet, a la vez que muchas veces se encuentran ajenos a los marcos institucionales jurídicos que determinan las partes.

En los contratos internacionales entre dos personas (físicas o jurídicas) que operan en distintos países, muchas veces las partes acuerdan que ante cualquier disputa, la misma se regirá bajo una determinada jurisdicción, lo cual implica que una de las partes a pesar de comprar recursos, producir y vender productos finales bajo la órbita de un Estado-nacional no estará atada a resolver litigios según la legislación de dicha nación, sino bajo la legislación de una tercera.

Muchos economistas y abogados afirmarían que es inconcebible la provisión de un «orden legal» en forma voluntaria entre las partes, sin embargo, en la arena internacional esto es lo que precisamente sucede.

La Organización Mundial de Comercio (OMC) intenta coordinar negociaciones para reducir barreras al comercio, pero no 
existe tal cosa como una justicia universal para demandar el cumplimiento de los contratos. Sin ello, ¿cómo es que estos intercambios son posibles y no nos encontramos con un constante incumplimiento de los compromisos?

La importancia del «enforcement» público en el comercio internacional es muy pequeña. La Escuela Austriaca sin embargo, a través de Hayek y sus seguidores plantea algunas respuestas. Recordemos que donde existen potenciales ganancias de intercambio los individuos buscarán formas de superar los obstáculos que se encuentren en su camino. Es por eso que han surgido el arbitraje internacional privado, el derecho comercial internacional privado o la Lex Mercatoria, y las tradiciones y costumbres para sancionar a los comerciantes que no cumplan con lo prometido. Estas instituciones, resultado de largos procesos evolutivos, son las responsables, en última instancia, de la gran aceleración que se vislumbra actualmente en el proceso de globalización, no los gobiernos.

\section{El arbitraje internacional}

En la actualidad, la mayoría de las disputas que surgen sobre la base de contratos internacionales no se resuelven ante el «enforcement público», sino bajo arbitraje internacional privado.

Al respecto, Julian Lew a través de un trabajo empírico especializado sobre este tema afirma que alrededor de un 80 por ciento de la resolución de disputas que surgen de los contratos de comercio exterior, se resuelven bajo arbitraje internacional privado, añadiendo que este número será cada vez mayor con el paso del tiempo. ${ }^{53}$

Esto ha generado, que desde 1990, un $90 \%$ de los contratos internacionales incluyan cláusulas de arbitraje internacional privado por la posibilidad de tener que incurrir en algún litigio.

53 Véase Julian D. M. Lew (1978), Applicable Law in International Commercial Arbitration: A Study in Commercial Arbitration Awards, Dobbs Ferry, New York, Oceana Publications, p. 589. 


\section{a) Los beneficios del arbitraje}

El arbitraje privado es una opción dentro de la literatura legal, y presenta numerosas ventajas en comparación con el «enforcement público». Veamos:

1) En primer lugar, el arbitraje puede bajar costes para resolver la disputa, fundamentalmente porque puede seleccionarse un árbitro que esté especializado en la materia pertinente específica.

Esta especialización significa que el arbitraje puede lograrse más rápidamente, y a menudo con menores gastos de litigio, puesto que las partes deben presentar menos información que si el caso fuera ante un juez inexperto en la materia.

2) Una nueva ventaja, y quizás de mayor grado que la anterior, se presenta debido a que en un arbitraje privado la rivalidad es menor, lo que puede permitir continuar con las relaciones de negocios, aún después de resolver la disputa.

3) Un tercer beneficio, es que de solicitarlo, el arbitraje puede mantenerse bajo privacidad.

4) Una cuarta ventaja, lo representa el hecho de que algunos empresarios prefieren evitar la aplicación de la legislación de la jurisdicción en la que operan y en consecuencia, atenerse a la legislación de la nación en la que opera su socio. Alternativamente, se plantea la posibilidad de elegir una tercera jurisdicción para ser neutral, y no beneficiar a ninguna de las partes.

5) A su vez, es un quinto beneficio el hecho de que se diseñe un proceso de selección para el árbitro. De esta forma se puede evitar el problema de que el árbitro sea de la misma nacionalidad que una de las partes, para lo cual se podrá llamar a un árbitro de un país neutro.

Sin embargo, existen numerosos críticos que afirman que el árbitro privado, a diferencia del juez tradicional, siempre está sujeto a ser corrompido. Esto ha dado lugar a procesos de selección de árbitros, concluyendo que no existe tal cosa. Hay un 
número importante de razones, explica Benson, sobre las que se esperaría que los incentivos de cooperación en la selección del árbitro que juzgará la disputa internacional serán sanos e incorruptibles. ${ }^{54}$

Una posibilidad de selección la constituye el establecer un ranking. Aquel que tiene más puntos es el elegido. Otra posibilidad es que una de las partes presente su propia selección de árbitros, y luego la otra parte va vetando los elegidos.

En toda selección las partes exigen ver el curriculum vitae del árbitro, donde toman contacto con su experiencia, su entrenamiento y los fallos que ha aplicado.

En este sentido Frank y Edna Elkouri afirman que los árbitros son elegidos por su especialización, por su experiencia, por su entrenamiento, y fundamentalmente por sus méritos e imparcialidad. Esto significa que cualquier caso de corrupción que se confirme, prácticamente terminará con la carrera del árbitro. Difícilmente un árbitro que haya acumulado experiencia y que se caracterice por su imparcialidad (que en definitiva son los elegidos) se preste a un caso de corrupción. ${ }^{55}$

\section{b) Las sanciones no legales del arbitraje}

Un segundo argumento en contra del arbitraje privado es que éste no tendría forma de sancionar a la parte perdedora. En otras palabras, ¿quién garantiza que la parte que pierde la disputa aceptará la decisión del árbitro?

La experiencia demuestra que son mínimos los casos en los que se acude al enforcement. Böckstiegal por ejemplo, explica que «estos argumentos tienden a sobredimensionar el problema. Toda investigación sobre la práctica del arbitraje internacional muestra que la gran mayoría de los arbitrajes se resuelven sin

54 Véase Bruce L. Benson (2000), «Arbitration», in Boudewijn Bouckaert and Gerrit De Geest (eds) Encyclopedia of Law and Economics, Vol. 5, Chelthenham, UK and Brookfield, US, Edward Elgar.

55 Véase Frank Elkouri y Edna Asper Elkouri (1985), How Arbitration Works, Washington, D.C., Bureau of National Affairs, Inc. 
necesidad del enforcement.» ${ }^{56}$ Y Bruce Benson extiende estas palabras al arbitraje local. ${ }^{57}$

Por otra parte, en la mayoría de los casos, explica David Charny, las partes deciden aceptar la decisión del arbitraje por las sanciones no legales que acarrean. En este sentido existe una larga literatura sobre incentivos privados como puede ser la reputación. Un ejemplo lo constituye el hecho mencionado con anterioridad en el que las partes de alguna manera pueden querer continuar la relación de comercio que venían manteniendo a pesar de la disputa, lo que implica que ambos estarán dispuestos a aceptar la decisión que surge del arbitraje..$^{58}$

Por otro lado, esto no constituye un problema en absoluto, puesto que el someterse al árbitro internacional privado no implica desplazar al juez tradicional. El demandante, siempre puede acudir al government enforcement si quiere asegurarse una sanción, aunque, por supuesto, deberá acudir en casi todos los casos a la jurisdicción del demandado. Así, el arbitraje privado, a pesar de ser el sistema de resolución de conflictos internacionales más elegido por las ventajas y beneficios que acarrea, se convierte en un complemento del hoy existente «enforcement público», pero no en su sustituto.

Otro caso puede ser el del coste, tanto en dinero como en tiempo, señalado también arriba. Ambas partes quizás acepten el arbitraje para evitar demoras en la resolución y también para evitar incurrir en costes económicos mayores al tener que presentar todas las pruebas ante el sistema tradicional.

Sintetizando, J.C. Chen explica que los beneficios del arbitraje señalados, operan como un poderoso incentivo para aceptarlo, y una de estas ventajas es que los comerciantes internacionales generalmente asumen que las cortes nacionales no

56 Véase K. H. Böckstiegal (1984), Arbitration and State Enterprises: A Survey of the National and International State of Law and Practice, Deventer, Netherlands, Kluwer Law and Taxation Publishers.

57 Véase Bruce L. Benson (1995), «An exploration of the impact of modern arbitration statutes on the development of arbitration in the United States», Journal of Law, Economics, \& Organization, 11.

58 Véase David Charny (1990), «Nonlegal sanctions in commercial relationships», Harvard Law Review, 104, pp. 409-412. 
forzarán obligaciones que se deriven sólo de las costumbres en las leyes comerciales. ${ }^{59}$

Esto es diferente a lo que se dio en la etapa medieval, cuando el sistema de la Lex Mercatoria era una realidad.

\section{La Lex Mercatoria o el derecho comercial internacional privado}

El sistema de la Lex Mercatoria medieval era un sistema casi puro de costumbres en el derecho comercial privadamente-arbitrado, y se manejaba simplemente por las sanciones privadas.

Para facilitar su negocio, los comerciantes desarrollaron su propio sistema legal. Se buscó proporcionar una rápida, barata y justa resolución de los conflictos comerciales. Esta Lex Mercatoria estableció instituciones y precedentes que han sobrevivido hasta el presente, y ahora encuentran su expresión en un extenso sistema de resolución alternativa (no estatal) de conflictos en los procedimientos de arbitraje. En algunos países, los comerciantes y los productores utilizaron en última instancia su influencia política, para incorporar sus propias instituciones legales en la ley estatal. Debido a la fragmentación política de Europa, los gobiernos que le hacían la vida demasiado difícil a los mercaderes, tendieron a alejar a los comerciantes y a sus negocios - y por lo tanto a su base tributaria- hacia las jurisdicciones competitivas, y la perspectiva de tales pérdidas motivó a los reguladores a frenar su depredación y conceder a los hombres de negocios espacio para maniobrar.

Este mismo sistema, es el que hoy rige en el comercio internacional; se trata de un derecho mundial independiente, aplicado a las transacciones comerciales, que se encuentra más allá de la órbita de los Estados y que viene a imponer competencia a una de las funciones que tradicionalmente se le asigna al Estado.

59 Véase J.C. Chen (1992), "Code, custom, and contract: the Uniform Commercial Code as Law Merchant», Texas International Law Journal, 27, 91-135. 
De Ly en este mismo sentido, afirma que la Lex Mercatoria es «un sistema policéntrico de instituciones que dan fuerza a reglas que se levantan a través de la práctica comercial y la costumbre.» ${ }^{60}$

\section{Tercera Conclusión}

Donde existen potenciales ganancias de intercambio, los individuos buscarán formas de superar los obstáculos que se encuentren en su camino. A lo largo de la historia, el proceso evolutivo del orden espontáneo ha dado lugar a numerosas instituciones que hoy se presentan imprescindibles para la vida social. Hemos observado en este trabajo que la vida social tal como la conocemos habría sido imposible sin estas instituciones, entre las que podemos destacar el lenguaje, la moneda o el sistema de precios. El derecho, por su parte, según observamos en el primer capítulo, no ha sido la excepción. Las normas legales en su mayoría, tienen su origen en los órdenes espontáneos, aunque esto no descarte por completo la importancia de la legislación.

El proceso de globalización da nacimiento así, a un derecho internacional privado, que según observamos arriba, es predominantemente un sistema policéntrico de costumbres, creado por el comercio entre comunidades a través de la negociación y la contratación y a través de los procesos de resolución de disputas. La negociación (a veces a través de un mediador) es el método dominante de resolución de conflictos, pero cuando se necesita una tercera parte para imponer una solución, la misma es casi siempre un árbitro internacional privado. Esta ley de costumbres y las soluciones de disputas a través de arbitraje emergen espontáneamente, cuando es necesario, e impone sanciones privadas. Sin embargo, estas sanciones son raramente utilizadas porque los beneficios del arbitraje y la aplicación de reglas propias originadas en las costumbres son substancialmente superiores a los costes.

60 Véase F. de Ly (1992), International business law and Lex Mercatoria, Amsterdam, North Holland. 
VI

\section{IMPLICACIONES DEL PROCESO DE GLOBALIZACIÓN SOBRE LA CULTURA}

El profesor canadiense Marshall McLuhan, acuñó a fines de la década de los sesenta, la expresión «aldea global» a los efectos de ilustrar cómo la electrónica convierte vastos espacios en comarcas reducidas (la «realidad virtual», luego sistematizada por Howard Rheingold). La revolución en las comunicaciones ha contribuido notablemente a estrechar los vínculos entre personas de muy diversos lugares.

El proceso de globalización que describimos sin duda tiene fuertes implicaciones sobre las sociedades en las que se introduce. Recordemos en este sentido las palabras de Mises, citadas arriba, en donde se observaban las dificultades que la sociedad inglesa vivió con la Revolución Industrial: «El sistema fabril evolucionó en continua lucha con innumerables obstáculos. Debió combatir prejuicios populares, antiguas costumbres establecidas, normas y reglamentaciones legales restrictivas.»

Sin embargo, la sociedad inglesa así como todas aquellas que abrazaron el progreso que implicó adaptarse a la Revolución Industrial, emergieron fortalecidas de aquella aceleración del proceso de globalización. Los estándares de vida dieron un salto nunca imaginado hasta entonces.

En este mismo sentido explicaba Hayek:

«Aunque la evolución cultural, lo mismo que el proceso civilizador que comporta, aportara a la humanidad los fenómenos de diferenciación, individualización, expansión del entorno social y aumento del bienestar, no puede decirse que este avance se produjera de manera suave y uniforme. En realidad, el hombre no ha logrado liberarse aún por completo de ciertas reminiscentes actitudes derivadas de la época tribal, en la que todos entre sí se conocían, ni han sido sus instintos neutralizados ni "ajustados" en la medida en que realmente lo exige nuestro relativamente reciente modelo de cooperación en un orden extenso.» ${ }^{61}$

61 Véase Friedrich A. von Hayek (1990) [1988], op. cit., p. 49. 
Existieron y siguen existiendo diversos grupos de personas anti-globalización que se resisten al cambio y prefieren abrazar los valores nacionales, lo conocido. En base a esta reflexión es que Juan José Sebreli, citado por Marcos Aguinis, decide diferenciarlos en dos grupos, el liberalismo por un lado, y el nacionalismo por otro:

«El liberalismo es individualista, el nacionalismo colectivista; el liberalismo se basa en la razón, el nacionalismo en la emoción; el liberalismo es laico, el nacionalismo es católico; el liberalismo busca consolidar un sistema de partidos, el nacionalismo es movimientista; el liberalismo es pluralista, el nacionalismo cree en una doctrina única; el liberalismo se proyecta hacia el futuro y es modernista, el nacionalismo añora el pasado y es antimodernista; el liberalismo reivindica la cultura urbana, el nacionalismo la rural; el liberalismo es universalista, el nacionalismo es particularista; el liberalismo expresa el capitalismo, el nacionalismo prefiere cierto anticapitalismo romántico.»62

Pero fundamentalmente el liberalismo es cosmopolita. El liberalismo no entiende de fronteras, ni de nacionalidades, ni de banderas. Al respecto nos contaba, Jorge Luis Borges, quizás el escritor más importante que nos haya dado la historia de la humanidad: «Para mí, los estados, son producto de las fantasías de los hombres. ¿Cómo explicar de otro modo que al sur de una línea la tierra cambie de nombre?» ${ }^{63}$

\section{La cultura y la sociedad cosmopolita}

Pero, ¿qué implicaciones tiene el proceso de globalización para la cultura? Etimológicamente, explica Benegas Lynch, «la expresión "cultura" proviene de cultivarse. La fertilidad de los esfuerzos del

62 Véase Marcos Aguinis (2004), ¿Qué hacer? Bases para el renacimiento argentino, Planeta, Buenos Aires, pp. 75-76.

63 Véase Ana Barón, «Lo único que le falta es el Premio Nobel», Somos, Buenos Aires, pp. 38-40, 24 de febrero de 1978; en Mateo, Fernando, El Otro Borges (Buenos Aires: Editorial Equis, 1997). 
ser humano por cultivarse, es decir, por reducir su ignorancia, está en proporción directa a la posibilidad de contrastar sus conocimientos con otros. Sólo es posible la incorporación de fragmentos de tierra fértil, en el mar de ignorancia en el que nos debatimos, en la medida en que tenga lugar una discusión abierta. Se requiere mucho oxígeno: muchas puertas abiertas y ventanas abiertas de par en par. La cultura no pertenece a tal o cual latitud, es el resultado de innumerables aportaciones individuales en el contexto de un proceso evolutivo que no tiene término. Aludir a la "cultura nacional" es tan desatinado como referirse a la matemática asiática o a la física holandesa.» ${ }^{64}$

Así, la cultura jamás puede ser asignada a un lugar y mucho menos se puede atribuir a un ente colectivo. La nación no piensa, no crea, no razona ni produce nada. Son específicos individuos los que contribuyen a agregar partículas de conocimiento en un arduo camino sembrado de refutaciones y correcciones que enriquecen las contribuciones originales.

Y en este sentido, debemos citar al austriaco Karl Popper, quien extrapola su filosofía de la ciencia a las interconexiones culturales: muestra cómo la competencia de teorías en un contexto de refutaciones y corroboraciones provisionales es aplicable a las relaciones entre personas que provienen de latitudes muy distantes, comenzando por la civilización griega, fruto de las culturas del Mediterráneo, lo cual constituyó el leitmotiv de Homero y formó parte central de los estudios de Herodoto. Popper ejemplifica las ventajas de los contactos que se establecen entre diversas culturas con lo ocurrido en el campo de la música en la época de oro de Viena. En este sentido, se detiene a considerar las múltiples influencias -incluyendo la música popular turca- sobre Mozart, Beethoven, Brahms y Mahler.

Stefan Zweig, por su parte, nos cuenta a través de sus memorias de las reuniones en centros culturales, universidades y en los célebres cafés vieneses donde tenía conciencia de su etnia y

64 Véase Alberto Benegas Lynch (h) (1994b), «Nacionalismo: Cultura de la Incultura», Laissez Faire N. 2, Facultad de Ciencias Económicas, Universidad Francisco Marroquín, p. 6. 
donde se empleaban muy variadas lenguas para la comunicación. Así lo expresaba:

En Austria...«[...] confluían todas las corrientes de la cultura europea [...] Cada habitante era educado conscientemente en el sentido de lo supranacional, de lo cosmopolita, como ciudadano del mundo. [...]; solo las décadas próximas demostrarán qué crimen cometió Hitler en Viena cuando trató de nacionalizar y provincializar por la fuerza la ciudad, cuyo sentido y cultura radicaban justamente en el encuentro de los elementos más heterogéneos, en su condición de supranacionalidad espiritual.» ${ }^{65}$

Como es sabido, la explosión cultural a que nos referimos no se limitó a las composiciones musicales sino que se extendió a la economía, el derecho, la literatura y el psicoanálisis. Esta bendición fruto del acercamiento entre distintos pueblos fue luego barrida por los sicarios nazis. ${ }^{66}$

El proceso de globalización en todas las ciudades en las que opera crea precisamente un proceso similar al de aquella Viena, creando un orden extendido que no tiene fronteras. Al respecto, William Warren Bartley III, nos ilustra:

«He aquí nuevamente la expresión de Hayek, "el orden extendido". Esta idea tiene una fuerza extraordinaria, como también la tiene la explicación de Hayek del modo como el orden se extiende a través de la competencia de diversos tipos, en especial la competencia de conocimiento, la cual incluye a su vez la competencia de las tradiciones y de las instituciones que encarnan el conocimiento. En esta competencia, la información y las tradiciones e instituciones que se adecuan a la realidad son seleccionadas evolutivamente. Este orden extendido no tiene fronteras.» ${ }^{67}$

65 Véase Stefan Sweig (1942), El mundo de ayer: autobiografía, Editorial Claridad, Buenos Aires, pp. 22-23 y 31.

66 Véase Alberto Benegas Lynch (h), Identidad, Globalización y Sociedad Abierta, Fundación Hayek.

67 Véase William Warren Bartley III (1989), op. cit. 


\section{E1 Nacionalismo y la "cultura alambrada»}

La cultura entonces, no reconoce ubicación geográfica, es por naturaleza cosmopolita. El nacionalismo, en contraposición, pretende establecer una "cultura alambrada» ${ }^{68}$, una cultura cercada que hay que preservar de la contaminación que provocarían aquellos contribuciones generadas fuera de las fronteras de la nación. Se considera que lo autóctono es siempre un valor y lo foráneo un des-valor, con lo que se destroza la cultura para convertirla en una especie de narcisismo de trogloditas que cada vez se asimila más a lo tribal que al espíritu cultivado que es necesariamente cosmopolita.

Por supuesto, el afecto al lugar en el que uno ha nacido, estudiado, vivido así como el apego a las buenas tradiciones es natural, incluso bueno para el progreso; pero distinto es declamar un irrefrenable amor telúrico que abarcaría toda la tierra de un país apartando otros lugares y otras personas que, miradas objetivamente, pueden tener mayor afinidad y cercanía pero que se dejan de lado solo porque están del otro lado de una siempre artificial frontera política.

El nacionalismo, en última instancia, no es algo natural, sino que es fruto de la ingeniería social, impuesto por la fuerza. Probablemente nada haya más antinatural que la delimitación de las fronteras, que son el resultado de acuerdos entre partes beligerantes, luchas y conquistas.

En este sentido argumenta Aurel Kolnai:

«La sociedad humana no está compuesta por naciones en el mismo sentido claro y definido en que está integrada por individuos o por estados soberanos. El espectro de las nacionalidades abunda en interpretaciones, ambigüedades y zonas crepusculares. En consecuencia, el concepto de nacionalismo (como principio universal), el concepto de un orden de estados nacionales "justo" o "natural" es, en la realidad y en la teoría, puramente utópico. No puede existir un orden de estados o de panteras en el cual no

68 Este término corresponde a Alberto Benegas Lynch (h) (1994b), op. cit. 
intervenga en grado sumo el factor de la arbitrariedad, la contingencia y el accidente histórico.» ${ }^{69}$

Sin embargo, los nacionalistas afirman que las naciones tienen un lenguaje, un etnia, una religión, una historia común, lo cual, siempre según este criterio, haría que la formación de naciones sea producto de un «devenir natural.»

Pero esto es una terrible falacia. Canadá o Suiza, por ejemplo, son naciones en las que sus habitantes no comparten un idioma común. En América Latina sin embargo, se comparte el mismo idioma y sin embargo constituyen varias naciones.

\section{Cuarta conclusión}

La cultura, según explicamos en el primer capítulo, es también un proceso que surge, en términos generales, de un orden espontáneo, es decir, de una serie de interrelaciones sociales, la cual lleva a un estado de cosas tal que hubiera sido imposible de planear por sólo un ser humano. En un sentido más restringido, sin embargo, y según lo que se explicó en este mismo apartado, la cultura proviene etimológicamente de «cultivarse», para lo cual es necesaria una «discusión abierta», «mucho oxígeno", "puertas $\mathrm{y}$ ventanas abiertas de par en par», pero fundamentalmente «fronteras abiertas».

El nacionalismo sin embargo, propone exactamente lo opuesto. Aquellos que se abrazan a los valores patrios y declaman un irrefrenable amor telúrico hacia su país y su «cultura alambrada» se mueven dentro de la caverna de Platón, donde todo es oscuridad, aunque conocido.

La globalización, viene a «traer la buena nueva». El proceso de globalización crea una sociedad cosmopolita, en la que no existen diferencias de raza, religión, etnias, ni nada por el estilo. Cada

69 Véase Aurel Kolnai (1946-1947), «Les amigüités nationales», en La Nouvelle Reléve, Montreal, pp. 533-546, 644-655. Publicado en inglés con el título «The Politics of National Diversity», The Salisbury Review, vol. 5, N. 3, abril de 1987, pp. 33-37. Citado por W.W. Bartley III (1989), op. cit. 
sociedad, se enriquece (no sólo económicamente) de su interrelación con otras sociedades.

Jamás podremos decir que una sociedad es libre, que el proceso de globalización se encuentra operando en su máximo esplendor, mientras no se abran las fronteras, mientras se limiten políticamente las interrelaciones sociales y comerciales, mientras se impidan los movimientos migratorios.

Quizás sean estos últimos, quienes mayor fuerza le otorguen a la «globalización cultural y cosmopolita» que aquí estudiamos. Los movimientos migratorios en definitiva, movilizan el conocimiento, introducen modificaciones adicionales a la historia común y enriquecen la cultura.

\section{REFERENCIAS BIBLIOGRÁFICAS}

Aguinis, Marcos (2004): ¿Qué hacer? Bases para el renacimiento argentino, Planeta, Buenos Aires.

ÁvilA, Jorge (2004): ¿Qué es la globalización? Consecuencias para la Argentina y la región, Fundación Atlas 1853, conferencia presentada en el Congreso de la Nación, 15 de septiembre de 2004.

Bartley III, William WarRen (1989): Desaparecen las fronteras. América en la Comunidad Mundial, Alocución pronunciada en la Reunión Anual de la Southwestern Social Science Association, Little Rock, Arkansas, el 30 de marzo de 1989.

Benegas Lynch (h), Alberto y Jackisch, Carlota (2003a): El fin de las libertades: el caso de la ingeniería social, Fundación Friedrich A. von Hayek, en colaboración con Guillermo Rodríguez y Roberto Dania.

Benegas Lynch (H), Alberto (2003): Identidad, Globalización y Sociedad Abierta, Fundación Hayek.

Benegas Lynch (H), AlberTo y JACKISCH, CARLOTA (2002): Librecambio y división de poderes, Fundación Hayek y Ediciones Lumiere SA, Buenos Aires.

Benegas Lynch (H), Alberto (1994a): Fundamentos de Análisis Económico, Abeledo-Perrot, Buenos Aires. 
- (1994b): «Nacionalismo: Cultura de la Incultura», Laissez Faire N.․․ 2, Revista de la Facultad de Ciencias Económicas, Universidad Francisco Marroquín.

BENSON, BRUCE L. (2000): «Arbitration», en Boudewijn Bouckaert y Gerrit de Geest (eds.) Encyclopedia of Law and Economics, Vol. 5, Chelthenham, UK and Brookfield, US, Edward Elgar.

- (1996): «Las instituciones y la evolución espontánea de la moralidad», Libertas N.ㅇ 24, ESEADE, Buenos Aires.

- (1995): «An exploration of the impact of modern arbitration statutes on the development of arbitration in the United States», Journal of Law, Economics, E Organization, 11.

Böckstiegal, K.-H. (1984): Arbitration and State Enterprises: A Survey of the National and International State of Law and Practice, Deventer, Netherlands, Kluwer Law and Taxation Publishers,

ChARNY, DAVID (1990): «Nonlegal sanctions in commercial relationships», Harvard Law Review, 104.

CHEN, J.C. (1992): «Code, custom, and contract: the Uniform Commercial Code as Law Merchant», Texas International Law Journal, 27, 91-135.

De Pablo, Juan Carlos (2001): La Globalización y cada uno de nosotros, Consejo Empresarial Argentino.

DE Ly, F. (1992): International business law and Lex Mercatoria, Amsterdam, North Holland.

Ebeling, Richard (2002): «Book Review: The Race to the Top: The Real Story of Globalization by Tomas Larsson», The Future of Freedom Foundation, February 2002. Traducido al español por Hernán Alberro para la Fundación Atlas para una Sociedad Libre, «La Carrera hacia la Cima, la verdadera historia de la globalización»

ElKoURI, Frank y ElKOURI, EdNA Asper (1985): How Arbitration Works, Washington, D.C., Bureau of National Affairs, Inc.

GALLo, EzeQUiel (1993), «Hayek y la investigación histórica, algunas reflexiones», Estudios Públicos, 50 (Otoño, 1993).

HaYeK, Friedrich A. von (1990) [1988]. La Fatal Arrogancia. Los Errores del Socialismo, ESEADE, Obras Completas, Volumen 1, Buenos Aires; y Unión Editorial, Madrid. 
- (1968): Individualismo: verdadero y falso, Centro de Estudios sobre la Libertad, Buenos Aires.

Herskovits, Melville. J. (1948): Man and His Works, Nueva York, Alfred A. Knopf, Inc.

- (1948): Economic Anthropology, A study in Comparative Economics, Nueva York, Alfred A. Knopf, Inc.

Huerta de Soto, Jesús (2002): Nuevos Estudios de Economía Politica, Unión Editorial, Madrid.

- (2001) [1998]. Dinero, Crédito Bancario y Ciclos Económicos, Unión Editorial, Madrid.

KeYNeS, John MAYNARD (1936): Teoría general de la ocupación, el interés y el dinero, Fondo de Cultura Económica, Serie de Economía.

LANDEs, DAvid (1979): Progreso Tecnológico y Revolución Industrial, Editorial Tecnos.

LARSSON, TOMAS (2002): The Race to the Top: The Real Story of Globalization, The Cato Store.

LeakeY, Richard E. (1981): The Making of Mankind, Nueva York, Dutton.

Lew, Julian D.M. (1978): Applicable Law in International Commercial Arbitration: A Study in Commercial Arbitration Awards, Dobbs Ferry, New York, Oceana Publications.

MAYER, CHRISTOPHER (2002): «Japan's Bust: An Austrian Critique of the Fed's Explanation", The Quarterly Journal of Austrian Economics, vol. 5, N.. 2 (Summer 2002), Ludwig von Mises Institute.

Menger, CARL (1963): Problems of Economics and Sociology, University of Illinois Press, Urbana.

Mises, Ludwig von (1959): Seis conferencias en Buenos Aires, Centro de Difusión de la Economía Libre, Buenos Aires.

- (2001) [1949]. La acción humana: Tratado de Economía, 6. ${ }^{\mathrm{a}}$ Edición, Unión Editorial, Madrid, España.

- (1997) [1953]. La teoría del dinero y del crédito, Unión Editorial, Madrid, España.

O'Rourke, Kevin H. y Williamson, Jefrrey G. (1999): Globalization and History, MIT Press.

Piggot, Stuart (1965): Ancient Europe from the beginning of Agriculture to Classical Antiquity, Edimburgo, Edimburgh University Press. 
Pirenne, Jacques (1934): Histoire des institutions et du droit privé de l'ancienne Egypte, Bruselas, edición de la Fondation Egyptologique Reine Elisabeth.

Powell, Benjamín (2002): «Explaining Japan Recession», The Quarterly Journal of Austrian Economics, Summer 2002, Volume 5, Number 2, Ludwig von Mises Institute.

RAVIER, ADRIÁN O. (2005): «El proceso de globalización desde una perspectiva hayekiana», Libertas N ․․ 45, ESEADE, Buenos Aires, pp. 243-363.

ROJAS, RICARDO (1990): «El orden jurídico espontáneo», Libertas N.. 13 , ESEADE, Buenos Aires.

Rothbard, Murray Newton (2004) [1962]: Man, Economy, and State, A Treatise on Economic Principles, Scholar's Edition; Edición en castellano autorizada por el Ludwig von Mises Institute, traducida por Norberto Sedaca, El Hombre, la Economía y el Estado, un Tratado sobre Principios de Economía, 1. ․ Edición, Buenos Aires, ESEADE, 2004, Volumen I.

RuEFF, JACQUES (1967): Balance of payments, Macmillan.

SennHOlz, Hans (2000): Globalization Under FIRE, Daily Article, Ludwig von Mises Institute.

SimONetTA, MARTín (2002): «Bases para la integración al mundo de la economía argentina», en Soluciones de Políticas Públicas para un País en Crisis, Fundación Atlas para una Sociedad Libre, julio 2002.

SKOUSEN, MARK (1993): «Who predicted the 1929 Crash?», incluído en The Meaning of Ludwig von Mises, Jeffrey M. Herbener (ed.), Kluwer Academic Publishers, Amsterdam, pp. 247284.

SMith, AdAm (1776): Investigación sobre la naturaleza y causas de la riqueza de las naciones, Fondo de Cultura Económica, Serie de Economía.

- (1759): The Theory of Moral Sentiments, Londres, A. Millar.

Sweig, STEFAn (1942): El mundo de ayer: autobiografía, Editorial Claridad, Buenos Aires.

Thurow, Lester (2000): Construir riqueza, Vergara.

ZANotTi, GABRiEL J. (2002): «La Globalización frente a la Escuela Austriaca de Economía», Management Herald, 5 de diciembre de 2002. 
- (1993): «Introducción Filosófica al Pensamiento de F.A. von Hayek», Estudios Públicos N.o 50, Chile, otoño 1993.

ZimMERMANN, EDUARDO A. (1987): «Hayek, la evolución cultural y sus críticos», Libertas N.․ 6, ESEADE, Buenos Aires. 